\title{
Transforming the U.S. Energy Infrastructure
}

L. E. Demick

The INL is a

U.S. Department of Energy National Laboratory

operated by

Battelle Energy Alliance

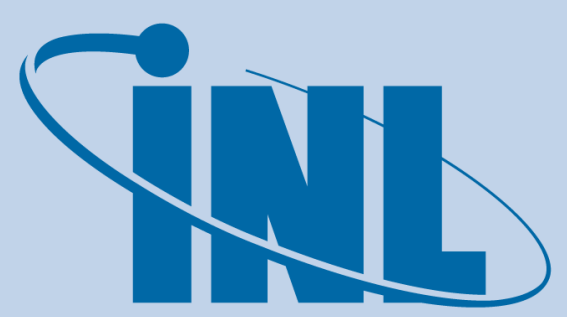

Idaho National Laboratory

July 2010

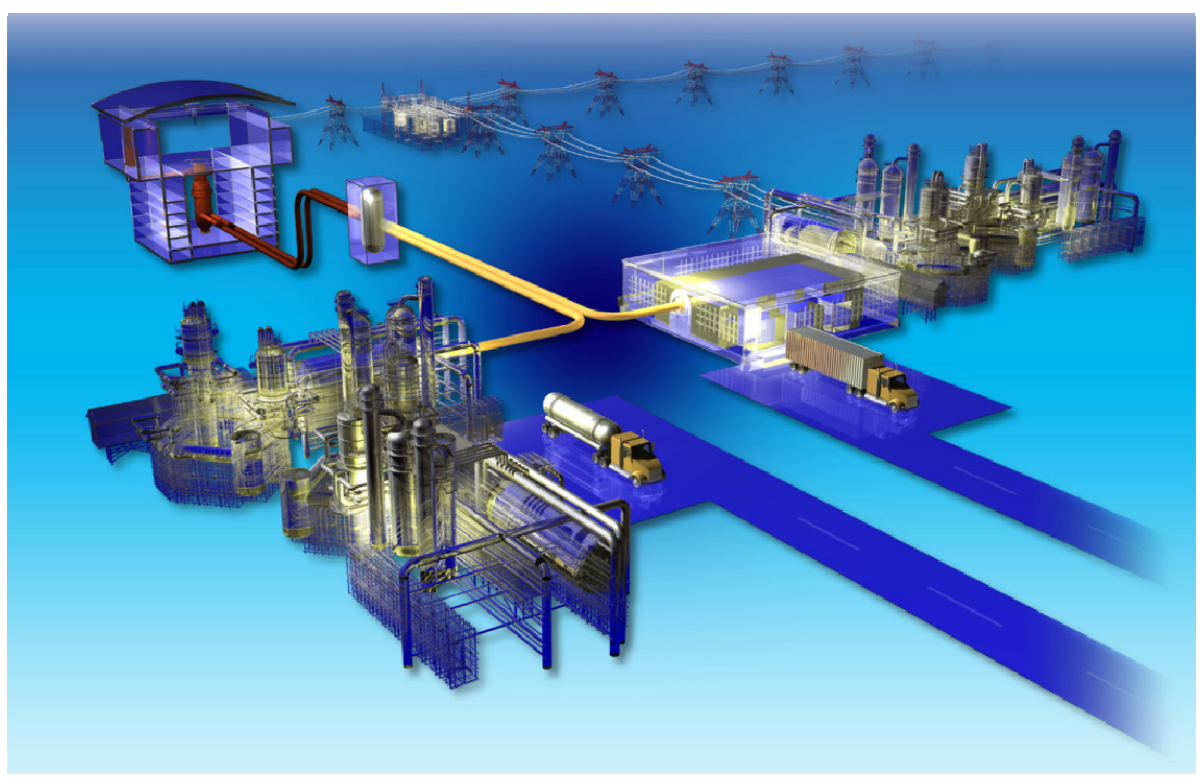




\section{DISCLAIMER}

This information was prepared as an account of work sponsored by an agency of the U.S. Government. Neither the U.S. Government nor any agency thereof, nor any of their employees, makes any warranty, expressed or implied, or assumes any legal liability or responsibility for the accuracy, completeness, or usefulness, of any information, apparatus, product, or process disclosed, or represents that its use would not infringe privately owned rights. References herein to any specific commercial product, process, or service by trade name, trade mark, manufacturer, or otherwise, does not necessarily constitute or imply its endorsement, recommendation, or favoring by the U.S. Government or any agency thereof. The views and opinions of authors expressed herein do not necessarily state or reflect those of the U.S. Government or any agency thereof. 


\title{
Transforming the U.S. Energy Infrastructure
}

\author{
L. E. Demick
}

July 2010

\section{Idaho National Laboratory Next Generation Nuclear Plant Project Idaho Falls, Idaho 83415}

Prepared for the

U.S. Department of Energy

Office of Nuclear Energy

Under DOE Idaho Operations Office

Contract DE-AC07-05ID14517 



\section{Next Generation Nuclear Plant Project}

\section{Transforming the U.S. Energy Infrastructure}

INL/EXT-09-17436

July 2010

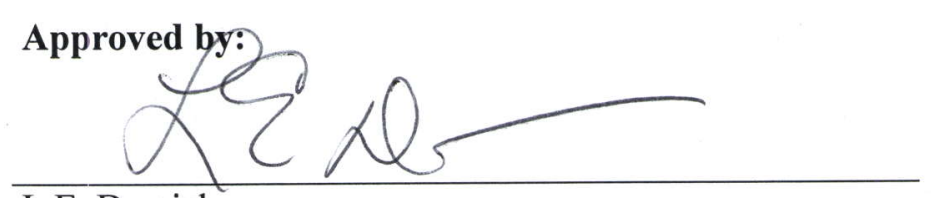

L.E. Demick

Author, Technical Consultant

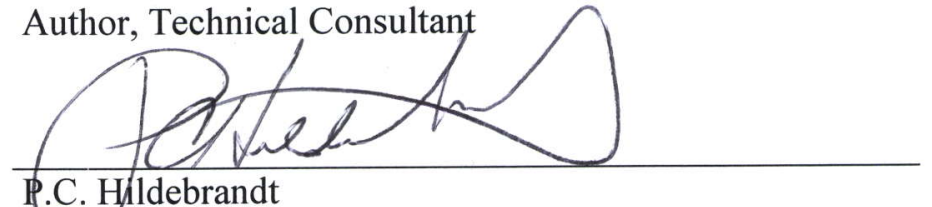

C. Hyldebrandt

Reviewer

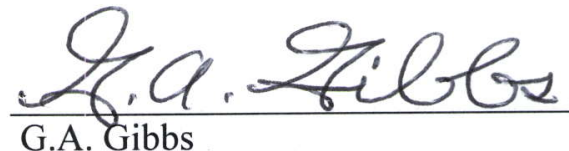

Approver, NGNP Project Director
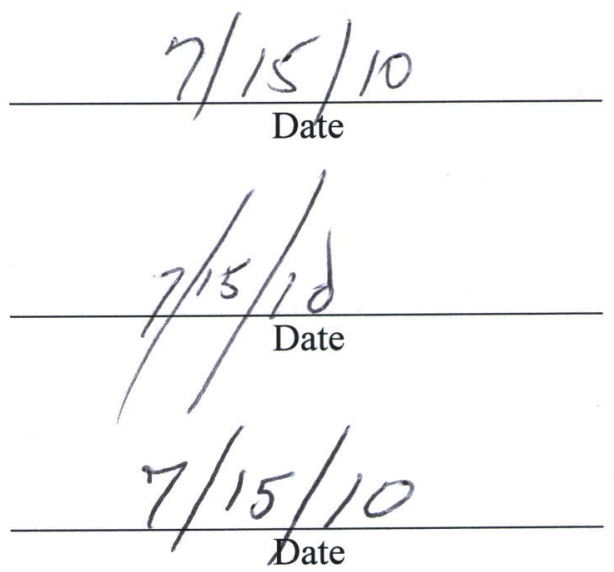



\section{EXECUTIVE SUMMARY}

The U.S. energy infrastructure is among the most reliable, accessible and economic in the world. On the other hand, the U.S. energy infrastructure relies heavily on foreign sources of energy, experiences high volatility in energy prices, does not practice good stewardship of finite indigenous energy resources and emits significant quantities of greenhouse gases (GHG). This report presents a Technology Based Strategy to achieve a full transformation of the U.S. energy infrastructure that corrects these negative issues while retaining the positives.

\section{Addressing Vulnerabilities in Energy Infrastructure}

The following are necessary to address all of the vulnerabilities in the energy infrastructure:

- Provide permanent and self-sustaining remedies that directly address the negative issues summarized above

- Maintain the reliability of the energy infrastructure

- Ensure that the impact of the transformation on the costs of energy reflect real costs for upgrade of the energy infrastructure

- Result in a predictable increase in the cost to the consumer of energy that is introduced consistently over the long term to facilitate accommodation of the increases on the individual and the economy

- Develop U.S.-based engineering, manufacturing and construction resources for implementation of the remedies, with the creation of permanent jobs and reduction in flow of capital offshore.

The above will not be achieved through the forces of the foreseeable competitive marketplace, but must be enabled through comprehensive and enduring U.S. Government energy and economic policies.

The U.S. energy infrastructure produces and consumes energy in three principal areas; (1) generating electricity primarily by the burning of coal (50\%), operating nuclear plants (20\%) and natural gas (20\%), renewable including hydro (10\%), (2) burning natural gas in residential, commercial and industrial applications, and (3) producing, refining and combusting crude oil based petroleum products and biomass based products, (e.g., corn ethanol) for transportation.

\section{Vulnerabilities in Energy Security}

In 2008, combustion of liquid fuels accounted for $\sim 40 \%$ of energy consumption; natural gas and coal combustion combined accounted for $\sim 46 \%$ and nuclear power, renewable and other forms of energy accounted for the remaining $\sim 14 \%$. The country relies heavily on imported crude oil $(\sim 9$ million barrels per day in 2009) and some natural gas to sustain the rate of consumption of these commodities. This has negative impacts:

- Reduces the security of our energy infrastructure by relying on foreign sources.

- Leads to price volatility; the prices of crude oil and natural gas have fluctuated over large ranges the past several years contributing to instability in the economics of sectors using these commodities.

- In burning of natural gas we are depleting a natural resource that has higher value for other purposes, such as feedstock for petrochemical processing.

- Our use of coal, the largest energy resource in the country, for electricity production is a major contributor to $\mathrm{CO}_{2}$ emissions. 


\section{Emissions}

From an emissions perspective, the large percentage of U.S. energy production and consumption that relies on the combustion of fossil fuels contributes to the United States being among the largest emitters of greenhouse gases (GHG), (e.g., $\mathrm{CO}_{2}$ ) in the world as follows:

- The United States is responsible for $\sim 1 / 3$ of the world-wide GHG emissions.

- The energy sector accounts for about $84 \%$ of the GHG emissions in the United States

- The global thrust to reduce emissions and the current Administration and Congressional objectives of pursuing massive reductions in GHG emissions contributes to the uncertainty in the economics of these fuels.

Referring to Figure E-1, the fraction referring to coal is from residential, commercial and industrial applications and is small and declining in time. The principal sources of the emissions from these sectors come from burning of coal and natural gas to produce electricity, burning of natural gas in residential, commercial and industrial applications and combustion of diesel, gasoline and ethanol in internal combustion engines and combustion turbines (e.g., airplane engines).

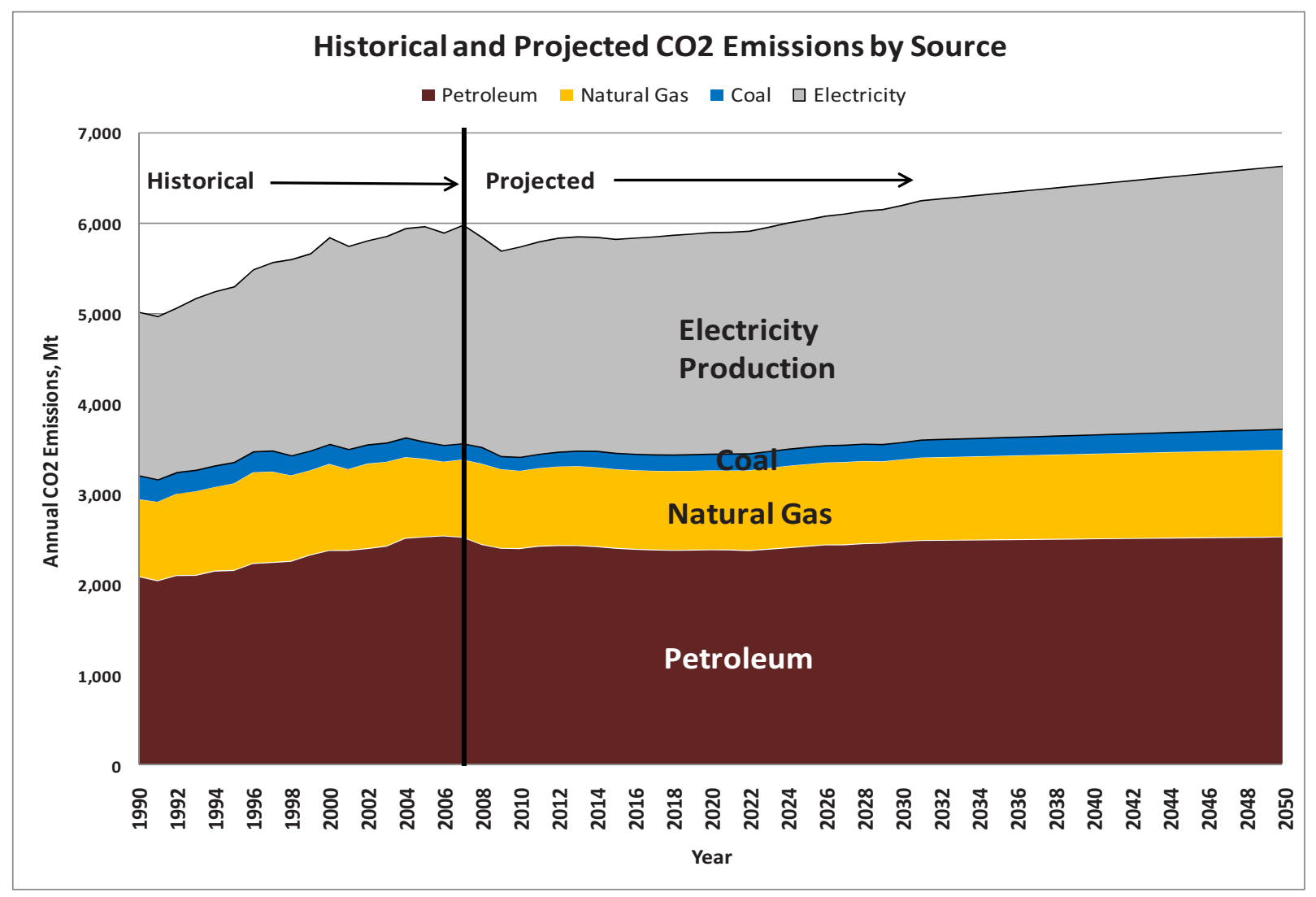

Figure E-1. Historical and projected emissions by source $1990-2050$.

\section{Approach}

This report summarizes evaluations performed by the Idaho National Laboratory (INL) in assessing alternatives and developing a strategy to effect potential changes in the way in which energy is produced and consumed that are necessary and sufficient to correct the negative issues in the U.S. energy infrastructure. The strategy achieves all four of the transformation objectives, (e.g., reduced GHG 
emissions and price volatility, and improved energy security and resource stewardship) on a straightforward and permanent basis using U.S. technology and industrial infrastructure. The detailed summary and basis for this strategy - the so-called Technology Based Strategy - is the subject of this paper.

A realistic approach to establishing a strategy for transforming the energy infrastructure requires maximizing flexibility as components of national energy policy change, energy economics change, and energy technologies advance. A common theme that should be considered is ensuring that options exist in energy production and use that can address changing needs. However, these type options can take one to two decades to commercialize - and are hence beyond the practical reach of typical private sector business investment, thus requiring support of government through government-industry partnerships.

The strategy described herein is based on contemporary policies, (e.g., ARRA) and what appear to be emerging policies, (e.g., pending legislation such as HR2454, S1733). It is also based on minimizing the risk of technology development required to achieve the objectives of this strategy. Whereas higher risk technologies are described and applied at a level consistent with its risk level, lower risk technologies are used for drawing conclusions for fulfilling the objectives for the policies being considered.

The strategy attacks the vulnerabilities of the energy infrastructure by first addressing the GHG emissions reduction objectives developed by policy papers of the Administration and being codified in Congressional pending legislation. Figure E-1 depicts the DOE Energy Information Administration (EIA) summary of current and projected $\mathrm{CO}_{2}$ emissions through 2050. These emissions are categorized in the four energy sectors shown in the figure. The data are shown in million metric tons of $\mathrm{CO}_{2}$ emitted per annum; shortened to Mt for convenience.

Figure E-2 shows the rate of reduction per annum and the total reductions that are required to meet the full emission reduction objectives of the Administration and Congress ( $\sim 5,640 \mathrm{Mt}$ below projections in 2050). It is clear from review of these two figures that there is no one area that can be targeted to achieve the objectives. All GHG emitting sectors must be addressed.

Figure E-3 shows the results of applying the Technology Based Strategy to emissions reductions. A five prong approach has been developed using available or in development technology.

The initiatives of the five prong approach include:

- Conservation \& Efficiency - Taking advantage of improving efficiency in energy production, consumption and conservation to reduce consumption at a rate of $\sim 0.25 \%$ per annum (consistent with EPA estimates but higher than projected by EIA with no emissions reduction program); reducing projected emissions in 2050 by $\sim 800 \mathrm{Mt}$

- Transportation Initiatives - Supporting more use of lower emitting transportation fuels in FLEX and hybrid vehicles, (e.g., replacing corn ethanol with cellulosic ethanol and/or other bio-fuels to improve environmental impact and reduce the impact on the food chain), use of bio-diesel in place of conventional diesel, improving vehicle mileage standards, (e.g., implementing proposed NHTSA CAFÉ standards), improving vehicle tailpipe emissions, (e.g., implementing the proposed EPA standards) and deploying hybrid and electric vehicles in place of conventional vehicles, reducing projected emissions in 2050 by $\sim 1000 \mathrm{Mt}$ and reducing the consumption of gasoline and diesel by 6.5 million barrels per day or about $70 \%$ of 2009 consumption of imported crude oil. 


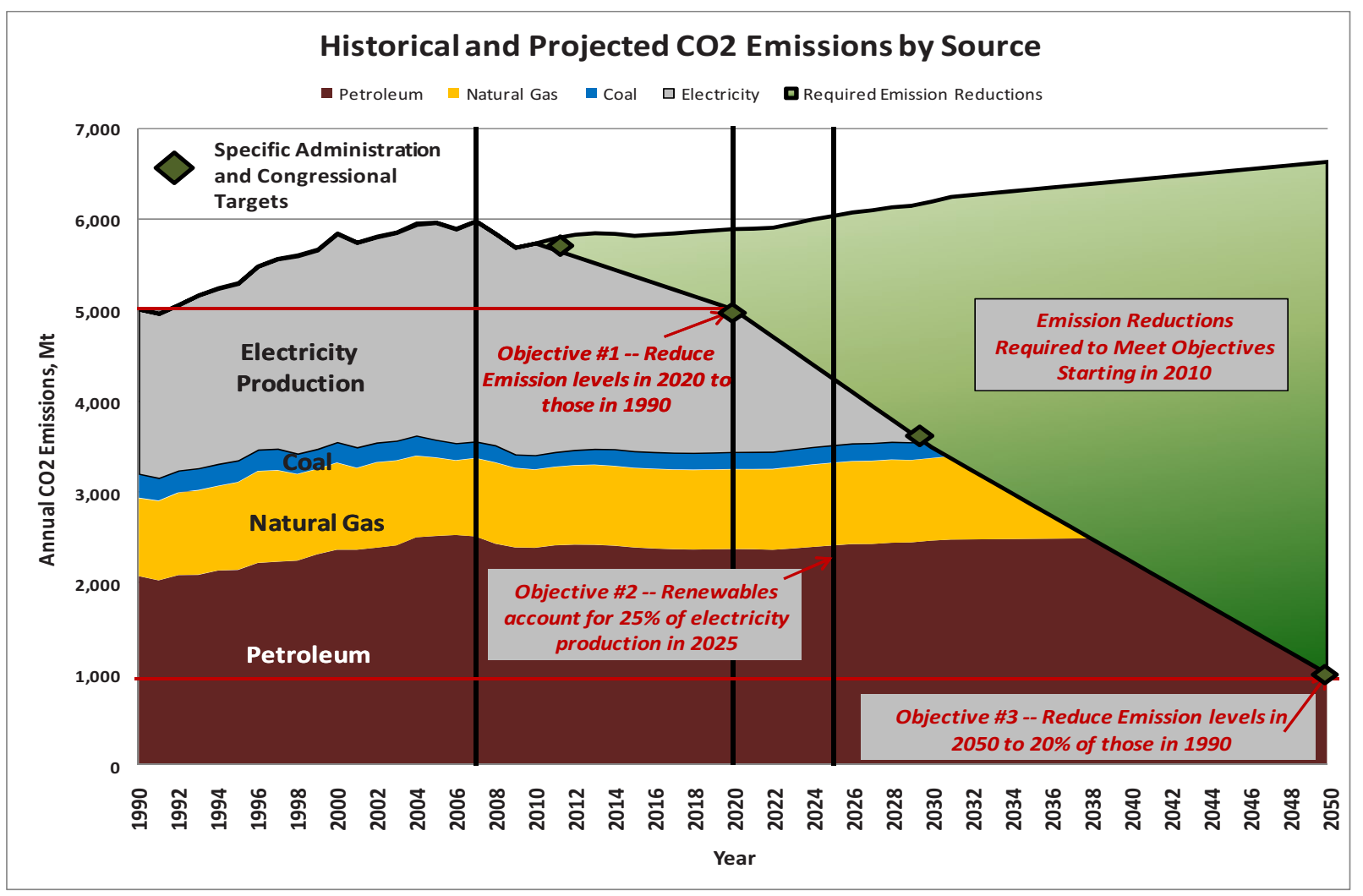

Figure E-2. Emission reductions required to meet objectives.

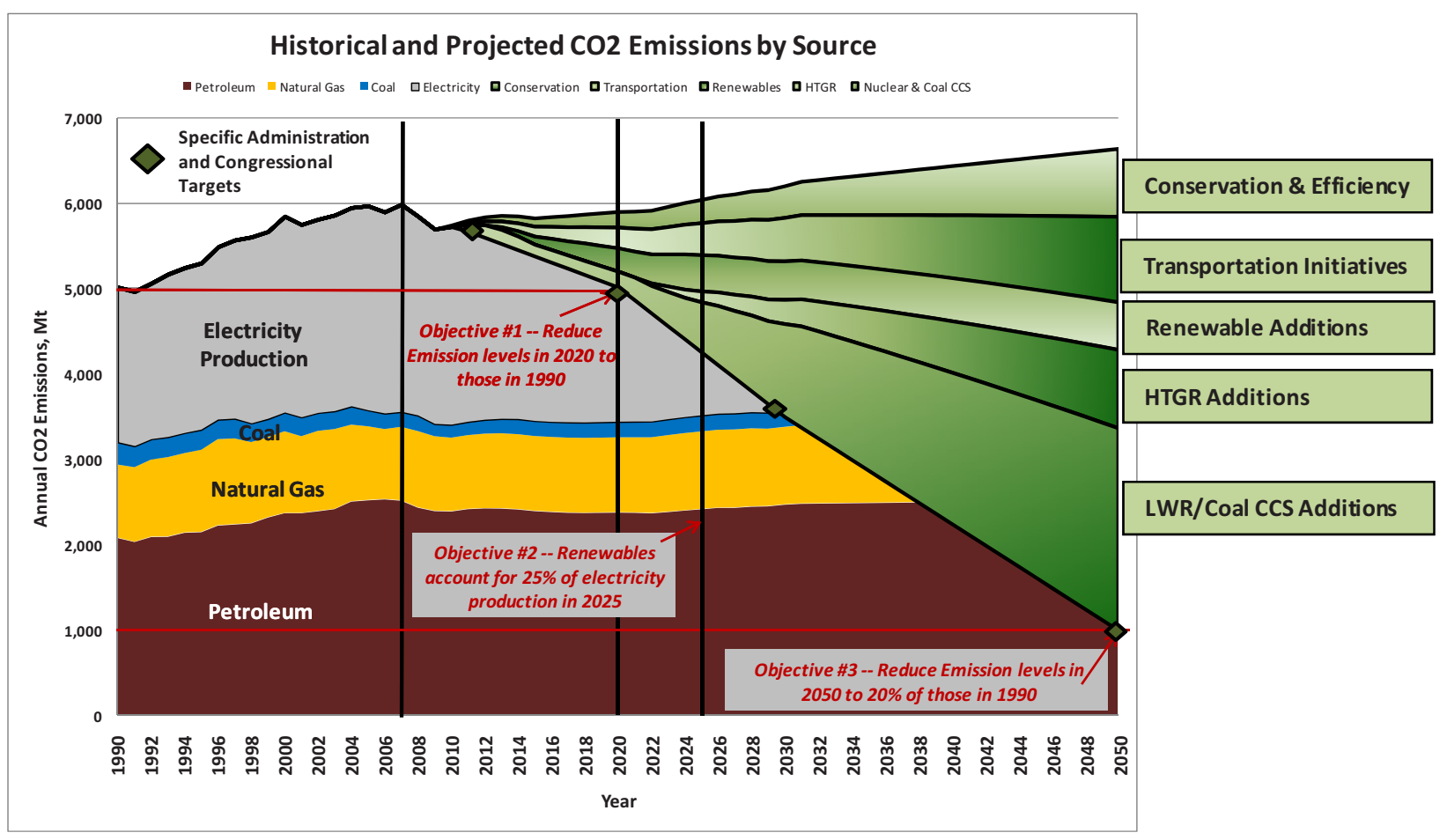

Figure E-3. Summary of the impact of all initiatives on reducing emissions. 
- Renewable Additions - Increasing the use of renewables for electricity production in place of coal plants, (e.g., hydro-electric, wind, solar, biomass); meeting the Administration and Congressional Objectives of having renewables account for $25 \%$ of electricity production by 2025 and maintaining this level of production through 2050. Achieving this objective would reduce projected emissions in 2050 by $\sim 560$ Mt. To meet this objective $\sim 125$ GWe (gigawatts electric) of renewable electric production will be required by 2025 and $\sim 160$ GWe by 2050 in addition to the capacity currently projected by EIA in these years.

- HTGR Additions - Applying nuclear energy, in the form of high temperature gas-cooled reactor (HTGR) technology to replace the burning of fossil fuels in commercial and industrial applications and to provide a GHG emission free source of energy for production of synthetic fuels from coal and biomass; reducing projected emissions in 2050 by $\sim 915 \mathrm{Mt}$ and producing 2.4 million barrels per day of gasoline, diesel and LPG; about $25 \%$ of the amount of crude oil imported per day in 2008. To meet this objective $\sim 260--2,400$ MWt (megawatt thermal) HTGR plants supplying energy to a wide range of industrial processes and $\sim 25-13,200$ Mwt HTGR /CTL plants would need to be deployed by 2050.

- LWR \& CCS Additions - Increasing the use of nuclear power and, if technically viable, coal and gas-fired plants with carbon capture and sequestration (CCS), as replacements for conventional coal fired and natural gas plants for the production of electricity; reducing projected emissions in 2050 by $\sim 2370$ Mt. To meet this objective $\sim 42$ GWe of CCS plants and $\sim 305$ GWe of nuclear power based electrical production would replace retired conventional coal and natural gas plants by 2050.

\section{Results of Completing the Strategy}

This Technology Based Strategy would result in a complete transformation that meets the criteria for correcting the vulnerabilities of the energy infrastructure in the United States:

- It will result in meeting the full objective of lowering greenhouse gas emissions on a permanent and self-sustaining basis using indigenous rather than offshore resources.

- It will result in more secure and more predictable costs of energy, (e.g., result in significant reductions, if not complete elimination, of the need to import crude oil or natural gas).

- It will promote more effective use of our indigenous sources of energy, (e.g., use of natural gas as feedstock for petrochemical processing instead of burning it, clean application of coal, our most abundant energy source).

It is estimated that full implementation of these initiatives would have a total cost of $\sim \$ 3,850 \mathrm{~B}$ (2007\$) over four decades ( $\angle \$ 100 \mathrm{~B}$ per year) and result in an increase of $\sim 54 \%$ in the real cost of energy by 2050 . These estimates are in the same range as the EPA estimates for implementation of the Congressional bills; (i.e., \$3,000B (2005\$) and a 51\% increase in the cost of energy). However the expenditures on the Technology Based Strategy have advantages when compared with current legislative proposals:

- The majority of the costs expended for the Technology Based Strategy would be for changes in the infrastructure rather than on the allowance and offset provisions of the current Congressional legislation that is being considered. The international offset provisions of these Congressional legislations result in a large flow of capital out of the country and do not reduce emissions in the United States.

- These expenditures would promote job growth in the suppliers to the energy sectors and in the energy sectors themselves. 
- Energy costs will be predictable and increases introduced gradually into the energy sectors allowing the economy to adjust over the long term.

The total costs estimated for the completion of these initiatives are a reasonable fraction of the U.S. GDP so will add significant numbers of jobs and stimulation to the production sector of the economy. About 8 million man years of effort is estimated required to complete the infrastructure changes over the 40 year period of this strategy. On average this would require an additional labor force over the 40 year period of about 200,000. About 350,000 permanent jobs would also be developed in the production portion of the revised energy infrastructure. An additional several hundred thousand jobs would be required to support continued operation, maintenance and upgrade of the revised energy infrastructure.

\section{Fulfilling National Interests}

These are national issues which require a national strategy and governmental commitment to address. The United States has the capabilities and has shown the ability to address these needs with innovation and economy. Consistent and focused attention to addressing these needs domestically could make the United States a principal competitive supplier of the technologies, engineering, equipment and construction methodologies internationally. Such an effort could spread to and reinvigorate the broader manufacturing industry in the United States potentially promoting a material shift toward a production oriented economy in the United States away from the services economy that has dominated the last few decades.

Clearly there is no single strategy that will be effective in meeting these challenges - and the best overall strategy will change over time. The strategy evaluated herein is a fully technical approach to address energy security, price volatility and preservation vulnerabilities of the current energy infrastructure and addresses the plants and processes that are responsible for emitting GHGs today. It is based on using technologies that are currently available or are being actively developed. This is not the only approach that could be taken nor could one be developed today that would be static in its implementation to address the emissions issues. Implementing any strategy will require:

- A long term consistent commitment by the government to provide the policies, requirements and incentives necessary for industry and the public to accept these objectives and the means to address them,

- A long term commitment from the government and the private sector to raise the necessary capital to make the changes,

- Adapting the best technologies from both technical as well as economic aspects, (e.g., the selection of technologies should be based strongly on economics), and

- A commitment to support identification and adoption of emerging and evolving technologies as they are shown to provide improved benefits over the longer standing technologies.

The objective in fleshing out the strategy developed herein is to scope the magnitude of the effort that will be required to address the negative issues in our energy infrastructure and to stimulate discussion of the objectives and the means to address them. 


\section{CONTENTS}

EXECUTIVE SUMMARY

1. INTRODUCTION 1

2. CURRENT AND PROJECTED ENERGY PRODUCTION AND CONSUMPTION .................... 4

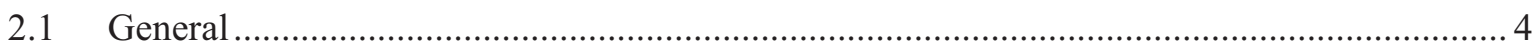

2.2 Energy Production, Consumption and GHG Emissions Projections versus GHG

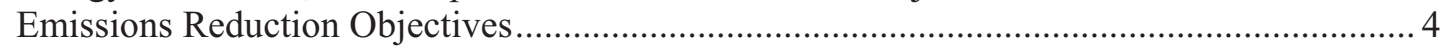

3. MEETING THE LONG-TERM ENERGY OBJECTIVES …................................................. 8

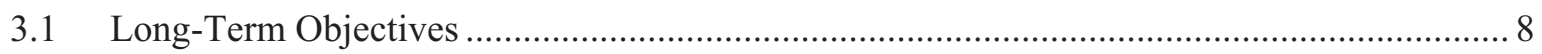

3.2 Cuts Needed to Meet Emission and Electricity Production Objectives ................................ 9

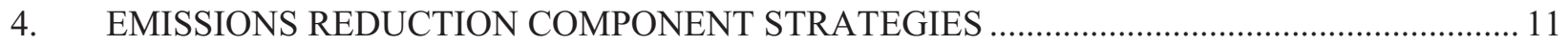

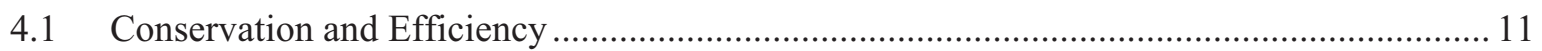

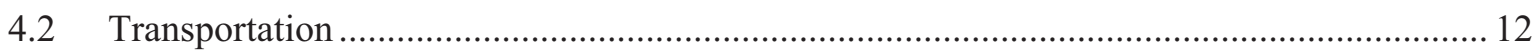

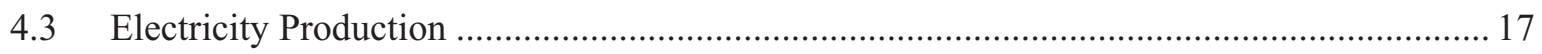

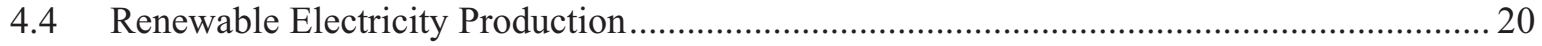

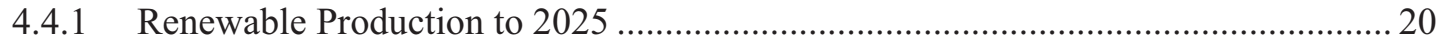

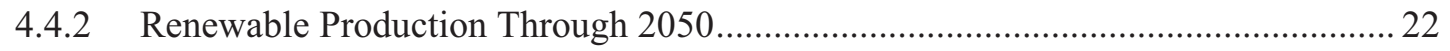

4.5 Electricity Production using Nuclear Power through 2020 .............................................. 25

4.6 Use of Nuclear Energy in the Industrial and Commercial Sectors..................................... 26

4.6.1 Supplying Process Heat and Energy to Industrial Processes .................................... 26

4.6.2 Biomass/Coal to Synthetic Liquid Fuels (BTL/CTL) ............................................. 27

4.6.3 Benefits of the Full Deployment of the HTGR Technology .....................................2 29

4.7 Deployment of Nuclear and Coal CCS Plants Through 2050 ............................................. 30

4.7.1 Deployment of Coal Plants with Carbon Capture and Sequestration (CCS) ............. 30

4.7.2 Deployment of Additional Advanced Light Water Reactors .................................... 31

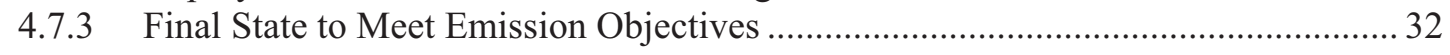

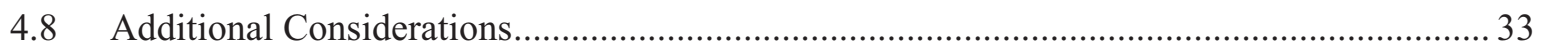

4.8.1 Infrastructure, Supply of Engineering, Materials and Equipment ........................... 33

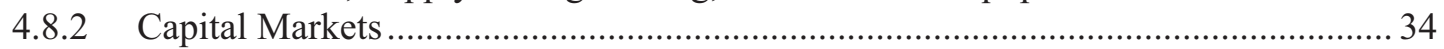

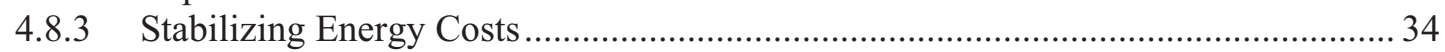

4.8.4 Reductions in Crude Oil Imports Improves Energy Security and Energy

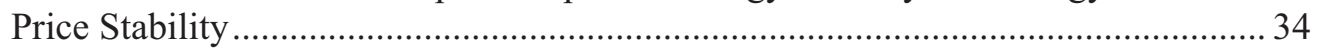

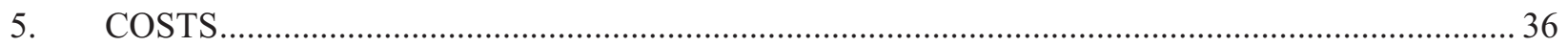

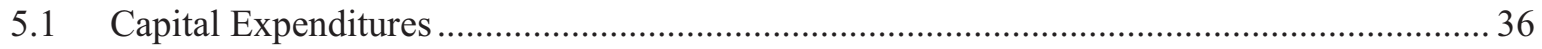

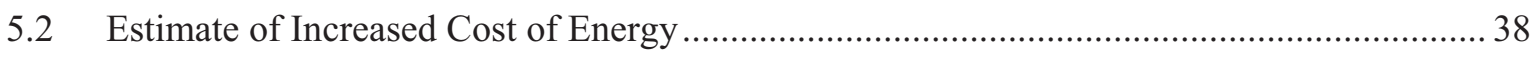

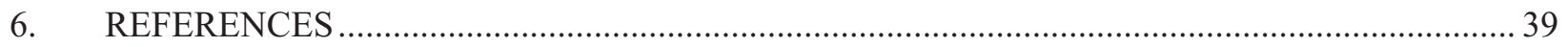

Appendix A-Summary of Administration and Congressional Objectives for Reducing Greenhouse Gas Emissions ...... 


\section{FIGURES}

Figure E-1. Historical and projected emissions by source $1990-2050$................................................vii

Figure E-2. Emission reductions required to meet objectives.................................................................ix

Figure E-3. Summary of the impact of all initiatives on reducing emissions. ..........................................ix

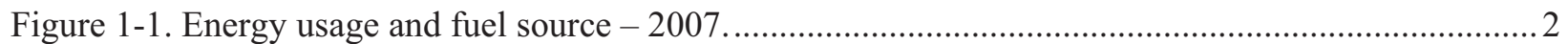

Figure 2-1. U.S. energy consumption and GHG emissions by source and sector in 2008 ......................5

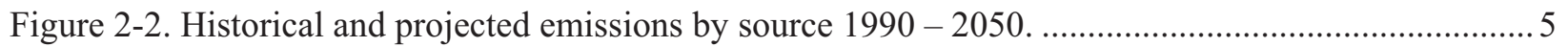

Figure 2-3. Emission Reductions Required to Meet Objectives ................................................................ 6

Figure 4-1. Emissions reductions from conservation and efficiency.................................................... 12

Figure 4-2. Emissions avoided by substituting cellulosic ethanol for corn ethanol and bio-diesel

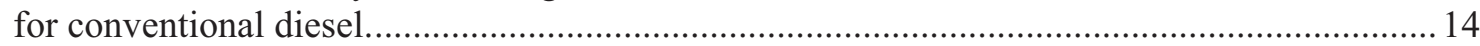

Figure 4-3. Annual emission reductions achieved from increased mileage standards............................ 15

Figure 4-4. Total avoided emissions from transportation initiatives. ................................................... 15

Figure 4-5. Liquid fuel consumption by sector and fuel type. [Table 11, Early Release of AEO 2010]

Figure 4-6. Net effect of conservation and efficiency and transportation initiatives on meeting the administration and Congressional objectives for emissions reductions.

Figure 4-7. Growth in renewable electricity production required to meet Objective \#2 compared with AEO2009a projections of renewable generation growth.

Figure 4-8. Emissions avoided by replacing coal generated electricity with renewable technologies.

Figure 4-9. Impact of conservation, transportation and renewable initiatives on meeting emissions Objective \#1 and renewable production Objective \#2 .......................................................... 25

Figure 4-10. Potential end users of HTGR and the number of plants available for use...........................27

Figure 4-11. Comparison of life-cycle emissions for several processes. ..................................................28

Figure 4-12. Summary of the impact of initiatives through HTGR Deployment on reducing

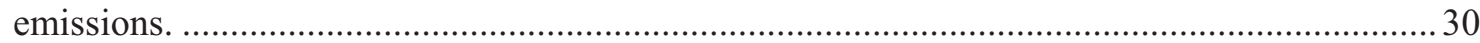

Figure 4-13. Summary of the impact of all initiatives on reducing emissions.......................................... 32

Figure 5-1. Estimate of accumulative costs for each scenario .............................................................. 36

Figure 5-2. Projected change in the cost of electricity production......................................................... 38

\section{TABLES}

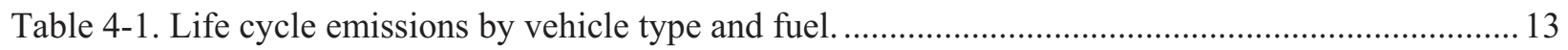

Table 4-2. Projected fuel savings for proposed 2012-2016 MY CAFÉ standards.................................. 16

Table 4-3. Impact of transportation sector emission reduction initiatives on gasoline and crude oil consumption in 2050 . 
Table 4-4. Characteristics of nonemitting sources of electricity production.

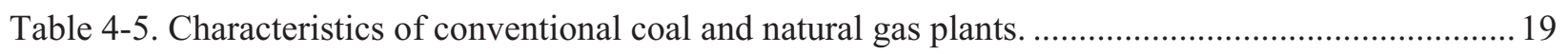

Table 4-6. Summary of capacity factors for electricity production. ...................................................... 19

Table 4-7. Summary of renewable electricity generation by technology in 2010 and 2025 ...................21

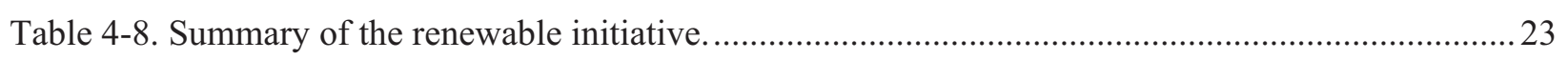

Table 4-9. Total avoided annual emissions in 2050 for transportation and renewable sectors.................24

Table 4-10. Deployment of HTGRs (all numbers are accumulative in time). ..........................................2 29

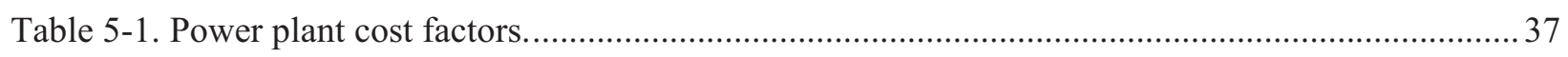

Table 5-2. Estimate of production costs for several electric power plants. ............................................. 37 


\title{
Transforming the U.S. Energy Infrastructure
}

\begin{abstract}
NOTE
The evaluations in this report pertaining to reductions in Greenhouse Gas Emissions were started in early 2009. These evaluations were based on the Obama-Biden Policy paper, "Promoting a Healthy Environment". Subsequently, Congressional bills were drafted to codify the emission reduction objectives of this paper; in the House, HR2454 has been passed and in the Senate, S1733 is still pending. Although, the objectives of these latter Congressional Bills for net emissions reductions are stated in different specific terms than the Obama-Biden Policy paper the results are materially the same. Accordingly, this draft report still uses the original Obama-Biden policy objectives for emissions reductions.

The majority of the specific data on energy generation and consumption and emissions used in this paper was originally developed from the March 2009 issue of DOE/EIA AEO2009. Where there were substantive differences the data of the evaluations were updated in this draft report using information from the April 2009 update of AEO2009 that takes into account the effects of the American Recovery and Reinvestment Act and from the early release of AEO2010 in December 2009.
\end{abstract}

\section{INTRODUCTION}

The U.S. energy infrastructure is among the most reliable, accessible and economic in the world. On the other hand, the U.S. energy infrastructure relies heavily on foreign sources of energy, experiences high volatility in energy prices, does not practice efficient stewardship of finite indigenous energy resources and emits significant quantities of greenhouse gases (GHG). This report presents a Technology Based Strategy to achieve a full transformation of the energy infrastructure that corrects these negative factors while retaining the positives.

The Technology Based Strategy was developed by the Idaho National Laboratory and has the following objectives:

- Provide permanent and self-sustaining remedies that directly address the issues, (e.g., achieve substantive and effective reductions in greenhouse gas emissions in the United States)

- Reduce the reliance on imported energy resources

- Provide stability in energy costs

- Optimize the use of indigenous natural energy resources, (e.g., coal, natural gas)

- Maintain the reliability of the energy infrastructure

- Ensure that the impact of the transformation on the costs of energy reflect real costs for upgrade of the energy infrastructure

- Result in a predictable increase in the cost to the consumer of energy that is introduced consistently over the long term to facilitate accommodation of the increases on the individual and the economy

- Develop U.S.-based engineering, manufacturing and construction resources for implementation of the remedies, with the creation of permanent jobs and reduction in flow of capital offshore.

These will not be achieved through the forces of the competitive marketplace, but must be enabled through comprehensive and enduring U.S. Government energy and economic policies. 
The production and consumption of energy in the United States is in four sectors; Residential, Commercial, Industrial and Transportation. As shown in Figure 1-1, the Industrial and Transportation sectors account for about the same fraction of the total energy and in total account for $\sim 60 \%$ of the usage. ${ }^{\text {a }}$ In 2008, combustion of liquid fuels accounted for $\sim 40 \%$ of energy consumption; natural gas and coal combustion combined accounted for $\sim 46 \%$ and nuclear power, renewable and other forms of energy accounted for the remaining $\sim 14 \%$. Coal, nuclear and renewable power account for the majority of the electricity production. The majority of the natural gas usage has traditionally been direct combustion in the residential, commercial and industrial sectors. Recently, there has been consideration of a shift from coal to natural gas for electricity production because of reductions in the price of natural gas and concerns with greenhouse gas emissions (natural gas produces about half the GHGs than coal per unit of energy). This has not yet affected the primary use of coal over natural gas in production of electricity.

The country relies heavily on imported crude oil and some natural gas to sustain the rate of consumption of these four sectors. This has negative impact on our energy infrastructure:

- It reduces the security of our energy infrastructure by relying on foreign sources.

- It leads to price volatility; the prices of crude oil and natural gas have fluctuated over large ranges the past several years contributing to instability in the economics of sectors using these commodities.

- In burning of natural gas we are depleting a natural resource that

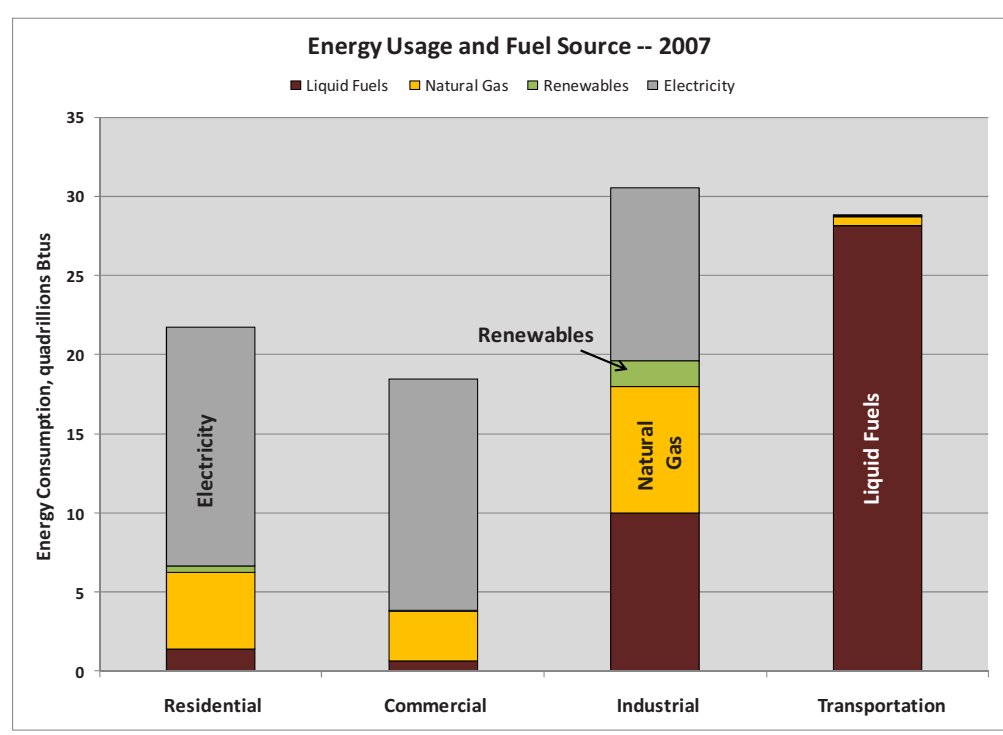

Figure 1-1. Energy usage and fuel source - 2007. has higher value for other purposes, such as feedstock for production of plastics.

- We are not using coal effectively, the largest energy resource in the United States.

The large percentage of U.S. energy production and consumption that relies on the combustion of fossil fuels contributes to the United States being among the largest emitters of greenhouse gases (GHG), (e.g., $\mathrm{CO}_{2}$ ) in the world.

- The United States accounts for about one-third of all GHG emissions world-wide

- The energy sector accounts for about $84 \%$ of the GHG emissions in the United States

- The global thrust to reduce emissions and the current Administration and Congressional objectives of pursuing massive reductions in GHG emissions contributes to the uncertainty in the economics of these fuels.

The current objectives of the Administration and Congress for reducing greenhouse gas emissions were used as the focus for developing the Technology Based Strategy. As the Strategy was developed additions to the emission reduction initiatives were made to address the other objectives, (e.g., use of

a. All of the energy production, consumption and emissions data in the report come from the DOE/EIA Annual Energy Outlook 2009 [2] 
HTGR technology for the production of synthetic fuels reduces the need to import crude oil; addressing the energy security and price volatility issues while also reducing emissions from use of more conventional processes.)

In this regard, the current Administration and the Congress have proposed national initiatives for significant reductions in GHG emissions over the next four decades. These are detailed in Administration Policy papers [Obama/Biden] and in pending Congressional legislation HR2454 (The American Clean energy and Security Act) [HR2454] and S1733 (The American Clean Jobs and Power Act of 2009) [S1733]. The Administration policy papers call for reductions in carbon dioxide and other GHG emissions to 1990 levels by 2020, increases in the use of renewable sources of electricity production by 2025 and reductions in carbon dioxide equivalent emissions to $20 \%$ of 1990 levels by 2050 . Although HR2454 and S1733 use different metrics to characterize the emissions reduction objectives, the result is the same as proposed in the Administration policy paper.

The portions of these bills that are relevant to development of the Technology Based Strategy are summarized in Appendix A.

The following first describes the major sectors in the energy infrastructure and their contributions to greenhouse gas emissions. Specific initiatives are then discussed with the objective of achieving the emissions reductions proposed by the Administration and Congress. Initiatives are included in five areas that address all four of the energy sectors:

- Conservation and Efficiency

- Transportation

- Renewable Power

- Application of HTGR Technology and

- Application of Nuclear Power and Coal with Carbon Capture and Sequestration.

The costs and benefits of these initiatives in resolving the other vulnerabilities of the current energy infrastructure are also summarized. 


\section{CURRENT AND PROJECTED ENERGY PRODUCTION AND CONSUMPTION}

\subsection{General}

The Department of Energy (DOE) Energy Information Administration (EIA) issues annual reports summarizing the characteristics of energy production and consumption in the United States and internationally. These include historical records as well as projections over the next 20 years of production and consumption by source of the energy, (e.g., coal, petroleum, natural gas, nuclear, renewable, including hydro and other), and by sector, (e.g., residential, industrial, commercial and transportation). The data includes the annual production and consumption of (1) energy in quadrillion Btus (QBtus), (2) electricity in billions of kilowatt hours (BKwhe) and (3) GHG emissions, (e.g., $\mathrm{CO}_{2}$ ) from use of fossil fuels in millions of metric tons (Mt).

The 2009 report, the Annual Energy Outlook 2009 (AEO2009) [AEO 2009] and the more recent Annual Energy Outlook 2010 Early Release [AEO 2010], were used extensively in developing the data of this report. Specifically, the historical data, (e., emissions in 1990 and 2000) and the projections (e.g., through 2030) were used as the baseline to establish the reductions in emissions that are required to meet the Administration and Congressional objectives. AEO2009 and AEO2010 only provide projections through 2030. To address the objectives of 2050, the AEO2009 and AEO 2010 data were extrapolated using linear projections developed from the projections 2010 through 2030.

\subsection{Energy Production, Consumption and GHG Emissions Projections versus GHG Emissions Reduction Objectives}

Figure 2-1 summarizes the U.S. energy consumption and emissions by energy source and sector of consumption in 2008 [AEO2009]. As shown the electric power and transportation sectors account for the majority of emissions. The emissions from the transportation sector are associated with the refining of crude oil and combustion of petroleum products, (e.g., gasoline and diesel) and ethanol. The emissions from the electric power sector come from coal and natural gas fired power plants. In 2008 these plants accounted for $68 \%$ of electricity production. $71 \%$ of the electricity was consumed in the residential and commercial sectors; $25 \%$ in the industrial sector.

Figure 2-2 shows the historical and projected levels of GHG emissions by energy source $1990-2050$. The data for this figure in the period 1990-2030 was taken directly from AEO2009. As noted above, the projections from 2030 to 2050 are based on extrapolation of the average annual rate of change in the AEO2009 data from 2010 to 2030. When the year-to-year increases are small, on the order of $1 \%$ or less, using linear projections rather than more complicated functions makes only a small difference in the final results. Figure 2-2 shows that EIA does not project any major changes in the relative usage of various energy forms, and therefore not in the $\mathrm{CO}_{2}$ emissions from the sources.

These curves reflect the current distributions of energy consumption and distribution and show that emission levels due to energy production and consumption are projected to increase at a lower rate over the next four decades than from 1990 - 2007. Note that the reductions in predicted emissions in 2008 and 2009 are believed to be due to the economic downturn in the United States those years. It is against these projections that the objectives of the Administration and the Congress are compared and the strategies to meet the proposed reductions in emissions and the distribution of electricity production are crafted. 


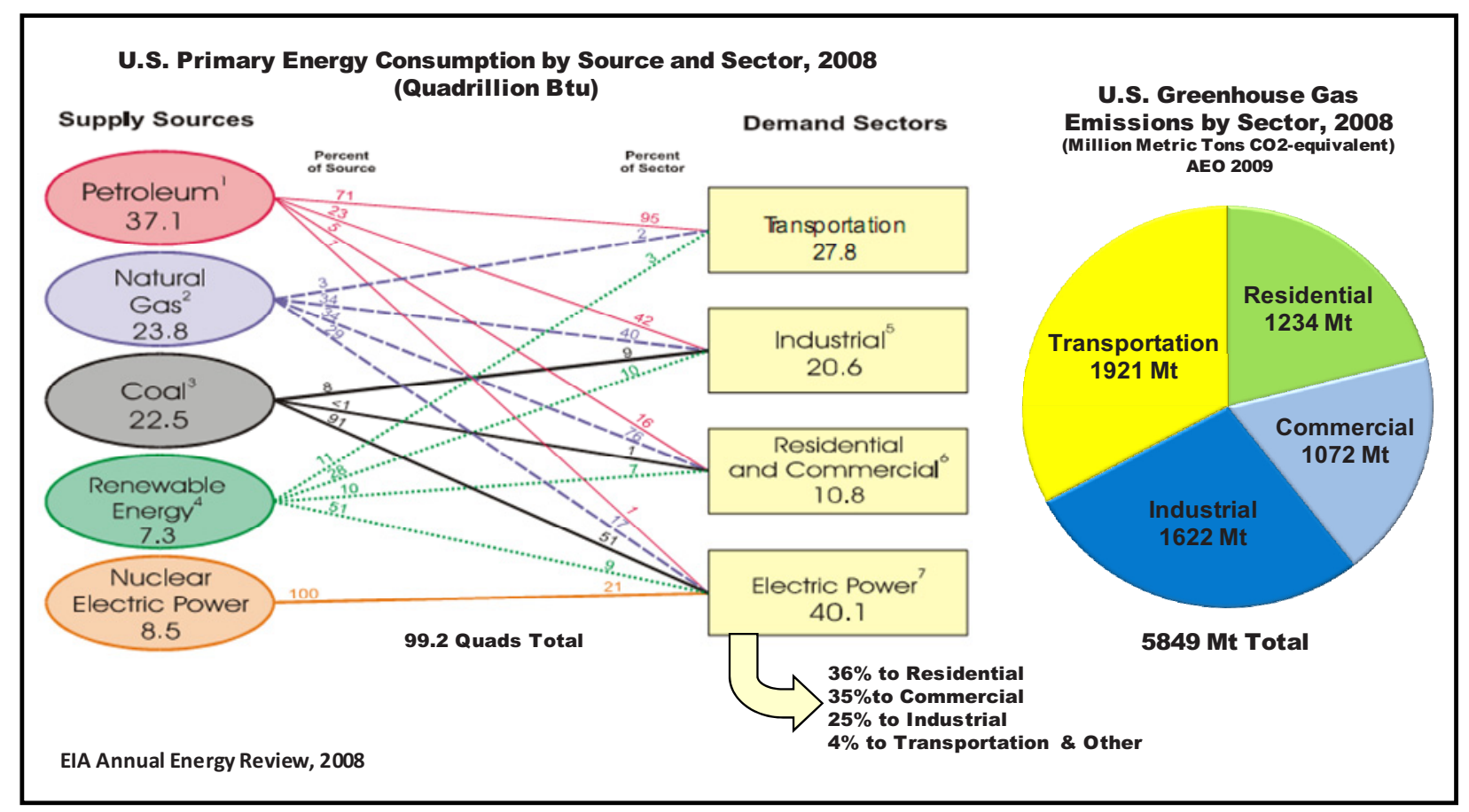

Figure 2-1. U.S. energy consumption and GHG emissions by source and sector in 2008.

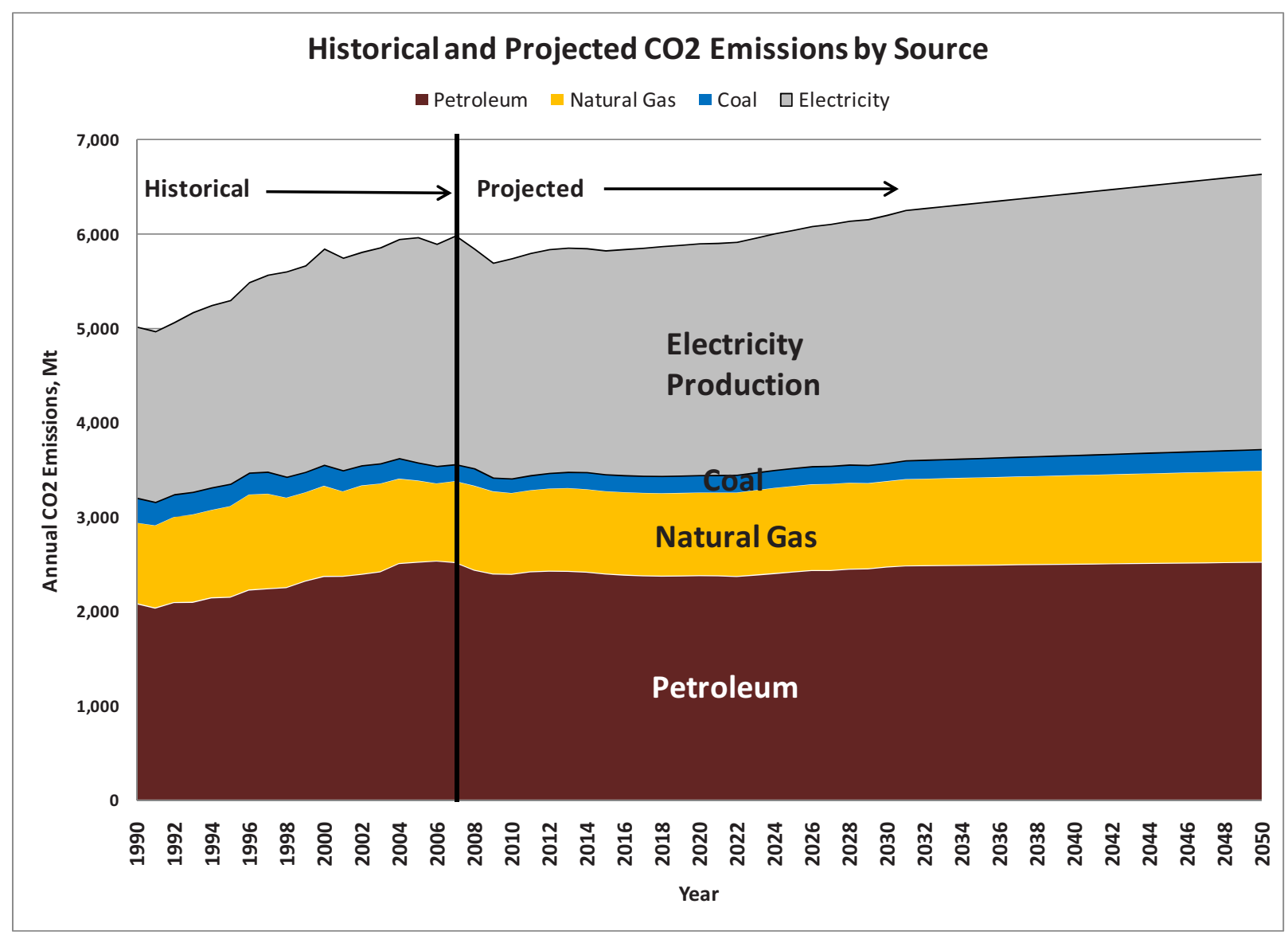

Figure 2-2. Historical and projected emissions by source $1990-2050$. 
Review of Figure 2-2 shows that petroleum usage and electricity production have the most impact on emissions; these are the principal areas to address to achieve significant reductions. It is noted, however, that even if all of the emissions currently projected for 2050 for electricity production and transportation were eliminated the emission reduction objectives would not be met. Cuts are also required in the emissions from natural gas used directly in the residential, industrial and commercial sectors. Coal as an energy source other than for electricity production is not a major factor in GHG emission reduction and is declining slightly in its use based on the EIA predictions.

Figure 2-3 shows the rate at which emission levels need to be cut to meet the Administration and Congressional objectives. As shown to meet objectives, $\sim 800 \mathrm{Mt}$ of GHG emissions must be reduced from the total projected in 2020 and $\sim 5,600 \mathrm{Mt}$ reduced in 2050. This will require reductions in every major energy production and consumption sector. The rate of change in emissions reductions shown on this chart was developed as a smooth fit to the administration objectives. An approach that affects a continuous reduction in emissions is judged to be more effective in utilization of resources, adapting new technologies, (e.g., bringing them on incrementally as they are proved beneficial) and for tracking of progress than an alternative which may address the reductions in a more step wise fashion.

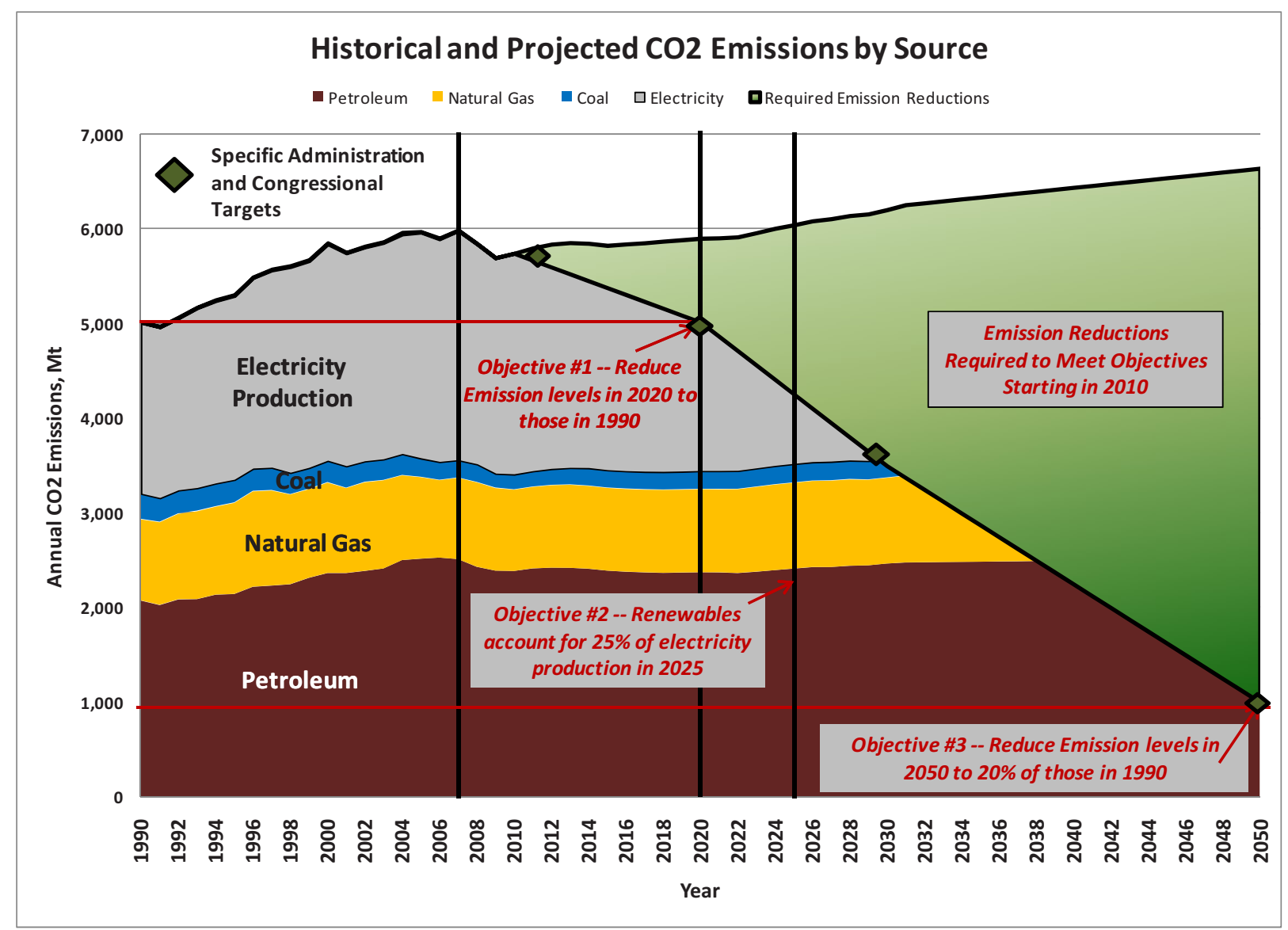

Figure 2-3. Emission Reductions Required to Meet Objectives

The reductions in emissions shown on Figure 2-3 begin in 2010. This is an aggressive assumption but is needed to improve the feasibility of meeting the objectives at the times cited. This requires that government policies, incentives and requirements be established and begin to be adopted in 2010. In fact, there are several areas where the country and industry are taking action independent of government policy that will lead to short term emissions reductions, (i.e., until the more significant initiatives evaluated 
herein can take effect). There is increasing emphasis on conserving energy consumption, industrial and commercial plants have initiatives to reduce their carbon footprints through shifting to less emitting sources of energy and increasing efficiency of their processes, the downturn in the economy has reduced consumption and increases in transportation fuel costs have reduced total miles driven and increased the sale of hybrid electric cars. Accordingly, some of the effort that is needed to meet the objectives is underway. However, rapid, focused and long term consistent government policies are required to achieve the full extent of the objectives. 


\section{MEETING THE LONG-TERM ENERGY OBJECTIVES}

\subsection{Long-Term Objectives}

The Administration and Congressional Objectives extend over the next 4 decades. They are focused on emissions reductions to address global warming concerns. As noted previously, however, there are other challenges to our use of energy that need to be addressed to support long term secure, stable and clean energy as collateral to meeting the objectives of emissions reductions. These include:

- Stabilizing the cost of energy - reduce volatility in the price of energy that has been experienced because of instability in the price of oil, natural gas and electricity; this is of particular interest to the private sector

- Ensuring the cost of energy supports growth of the economy and competitiveness internationally - a national objective

- Promoting security of the energy supply - reduce reliance on foreign sources (particularly those in unstable or anti-U.S. regions of the world); primarily a national interest and of interest to selected industries; petroleum and petro-chemical industries that import a significant fraction of feedstock

- Promoting development of the U.S. infrastructure supporting the energy supply; primarily of national interest and to large U.S. component and system suppliers to the energy sector. This covers as a minimum the following areas:

- Use of indigenous resources, (e.g., coal, gas, uranium)

- Research \& Development

- Engineering

- Equipment, component, system and material suppliers

- Contractors.

It is of importance that long term energy strategies consider these as well as the emission reduction objectives. This will take a balanced approach that draws on the factors inherent in the technologies in the U.S. energy infrastructure addressing all objectives and balancing the effectiveness, cost and reasonableness of each strategic component. To this end, addressing transformation in the following components of energy production and consumption is the focus of the strategy discussed herein:

- Conservation and Efficiency

- Transportation

- Industrial and Commercial Processes

- Electricity Production.

The following section quantifies the specific reductions in emissions and increase in renewable electricity production that are required to meet Administration and Congressional objectives. The remaining sections outline the initiatives in each of the energy production and consumption components for reducing emissions through conservation and efficiency, increasing the percentage of renewable and nuclear based electricity production, reducing combustion of fossil fuels in transportation through improved fleet mileage and more reliance on hybrid and electric vehicles and substituting nuclear energy technologies(i.e., the Advanced Light Water Reactor (ALWR) and High Temperature Gas-cooled Reactor (HTGR)) as energy supplies in place of fossil fuels. 


\subsection{Cuts Needed to Meet Emission and Electricity Production Objectives}

The following tables summarize the 1990 annual $\mathrm{CO}_{2}$ emissions by fuel and sector and then lists the differentials that would be required in each of these if each were to share in the same percentage of reduction to meet the objectives. As will be shown in following sections not all of these reductions can be realized by source and sector. Certain of the sources, (e.g., electricity production) will have to absorb more of the reductions.

To meet the Administration Objectives the following reductions in emissions from those projected by AEO2009 would be required:

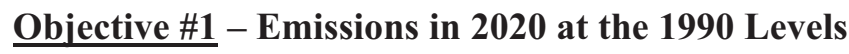

\begin{tabular}{|c|c|c|c|c|c|c|c|c|c|}
\hline \multirow{2}{*}{ Year } & \multirow{2}{*}{ Total, Mt } & \multicolumn{4}{|c|}{ Emissions by Fuel, Mt annually } & \multicolumn{4}{|c|}{ Emissions by Source, Mt annually } \\
\hline & & Natural Gas & Petroleum & Coal & Electricity & Residential & Commercial & Industrial & Transportation \\
\hline 1990 & 5,019 & 856 & 2077 & 265 & 1820 & 962 & 788 & 1687 & 1583 \\
\hline $2020 *$ & 5,905 & 878 & 2375 & 186 & 2466 & 1230 & 1192 & 1557 & 1929 \\
\hline Delta & 886 & 22 & 298 & -79 & 646 & 268 & 404 & -130 & 346 \\
\hline \multicolumn{10}{|c|}{ EIA Data and Projections AEO2009a April update } \\
\hline hese & he emiss & ns project & by EIA in & 0 if no & n is taken & & & & \\
\hline
\end{tabular}

\section{Objective \#2 - 25\% of Electricity Production is to be by renewable sources in 2025.}

EIA projects the following for 2025:

\begin{tabular}{|c|c|c|c|c|c|c|}
\hline \multirow[b]{2}{*}{ Source } & \multicolumn{3}{|c|}{2010} & \multicolumn{3}{|c|}{2025} \\
\hline & $\begin{array}{c}\text { Generation } \\
\text { BKWhe }\end{array}$ & $\%$ of Total & $\begin{array}{c}\text { Emissions } \\
\mathrm{Mt}\end{array}$ & $\begin{array}{c}\text { Generation } \\
\text { BKWhe }\end{array}$ & $\%$ of Total & $\begin{array}{c}\text { Emissions } \\
\mathrm{Mt}\end{array}$ \\
\hline Coal & 2,022 & $48.6 \%$ & 2117 & 2,202 & $45.5 \%$ & 2325 \\
\hline Petroleum & 56 & $1.3 \%$ & 2435 & 49 & $1.0 \%$ & 2454 \\
\hline Natural Gas \& Other Gases & 800 & $19.2 \%$ & 1182 & 930 & $19.2 \%$ & 1256 \\
\hline Nuclear & 809 & $19.5 \%$ & & 882 & $18.2 \%$ & \\
\hline Pumped Storage/Other & 6 & $0.1 \%$ & 12 & 6 & $0.1 \%$ & 12 \\
\hline Renewables* & 468 & $11.2 \%$ & & 771 & $15.9 \%$ & \\
\hline Total & 4,162 & & 5746 & 4,840 & & 6047 \\
\hline \multicolumn{7}{|c|}{ EIA Data and Projections AEO2009a April update } \\
\hline $\begin{array}{l}\text { * Includes conventional hydroel } \\
\text { and wind power. }\end{array}$ & c, geothermal, & lood, wood wa & municipal w & e, other bioma & solar thermal & otovoltaics, \\
\hline
\end{tabular}

To meet this objective renewable would have to account for 1210 BKWh of production $(25 \% \mathrm{x} 4840$ BKWhe) This is an increase in renewable production of $\sim 439$ BKWhe; it is about three times the renewable generation projected for 2010 and an increase of $\sim 57 \%$ above that currently projected by EIA for renewable production in 2025.

To meet this objective major changes are needed in the transportation sector, in electricity production and the use of natural gas. 
Objective \# 3 - Reduce emissions in 2050 to $20 \%$ of the 1990 levels.

\begin{tabular}{|c|c|c|c|c|c|c|c|c|c|}
\hline \multirow{2}{*}{ Year } & Total, Mt & \multicolumn{3}{|c|}{ Emissions by Fuel, Mt annually } & \multicolumn{4}{c|}{ Emissions by Source, Mt annually } \\
\cline { 3 - 11 } & Natural Gas & Petroleum & Coal & Electricity & Residential & Commercial & Industrial & Transportation \\
\hline 1990 & 5,019 & 856 & 2077 & 265 & 1820 & 962 & 788 & 1687 & 1583 \\
\hline $2050^{*}$ & 6,645 & 966 & 2518 & 231 & 2930 & 1422 & 1506 & 1470 & 2247 \\
\hline $20 \%$ of 1990 & 1,004 & 171 & 415 & 53 & 364 & 192 & 158 & 337 & 317 \\
\hline Delta & $\mathbf{5 , 6 4 1}$ & $\mathbf{7 9 5}$ & $\mathbf{2 , 1 0 3}$ & $\mathbf{1 7 8}$ & $\mathbf{2 , 5 6 6}$ & $\mathbf{1 , 2 3 0}$ & $\mathbf{1 , 3 4 8}$ & $\mathbf{1 , 1 3 2}$ & $\mathbf{1 , 9 3 0}$ \\
\hline
\end{tabular}

The following sections describe actions that could be taken over the next four decades in each of these sectors to meet the Administration and Congressional objectives on $\mathrm{CO}_{2}$ emissions. The impact of these initiatives on energy security through reductions in imports of foreign sources of energy is also identified. 


\section{EMISSIONS REDUCTION COMPONENT STRATEGIES}

\subsection{Conservation and Efficiency}

The EIA projections on energy consumption account for Federal and State programs that address conservation and efficiency improvements with the objective of reducing the energy consumption growth rate. These are applied in the projections for the growth of energy consumption in the residential, commercial and industrial sectors. They address the use of improved building efficiencies that affect heating and cooling requirements, more efficient lighting, heating and cooling equipment, more efficient use of energy in industrial processing. The specific legislation considered at the Federal level includes:

- National Appliance Energy Conservation Act of 1987

- Energy Policy Act of 1992

- Energy Policy Act of 2005

- Energy Independence and Security Act of 2007

- Energy Improvement and Extension Act of 2008

- American Recovery and Reinvestment Act of 2009F. ${ }^{b}$

Specific state initiatives are included in the EIA projections geographically.

For the purposes of this study it is assumed that if the initiatives proposed herein or in the proposed Congressional legislation are taken, there will be several factors that will result in reductions in the annual growth rate of energy consumption. This is assumed to occur by increased public awareness of the need to conserve, higher energy prices and industry programs in response to government requirements for higher efficiency in energy production and consumption and reductions in GHG emissions. The EPA analyses of HR2454 [EPA 2009a \& b] and S1733 [EPA 2009c] project that these effects would reduce energy consumption by $\sim 12 \%$ below the EIA projections in 2050 . This is an average annual reduction rate of $0.28 \%$ beginning in 2010 , (i.e., $\sim 50 \%$ of the annual growth rate in energy consumption predicted in [AEO2009a]). This rate of reduction is assumed herein and results in a total reduction of $\sim 800 \mathrm{Mt}$ of the emissions projected by the EIA in 2050.

Figure 4-1 shows the effect of the reductions in consumption due to Conservation and Efficiency on reducing the emissions baseline from which the remaining emissions reduction initiatives will be crafted to meet Administration and Congressional objectives.

b. The April update of AEO2009, (i.e., AEO2009a) accounted for the provisions of the ARRA of 2009 


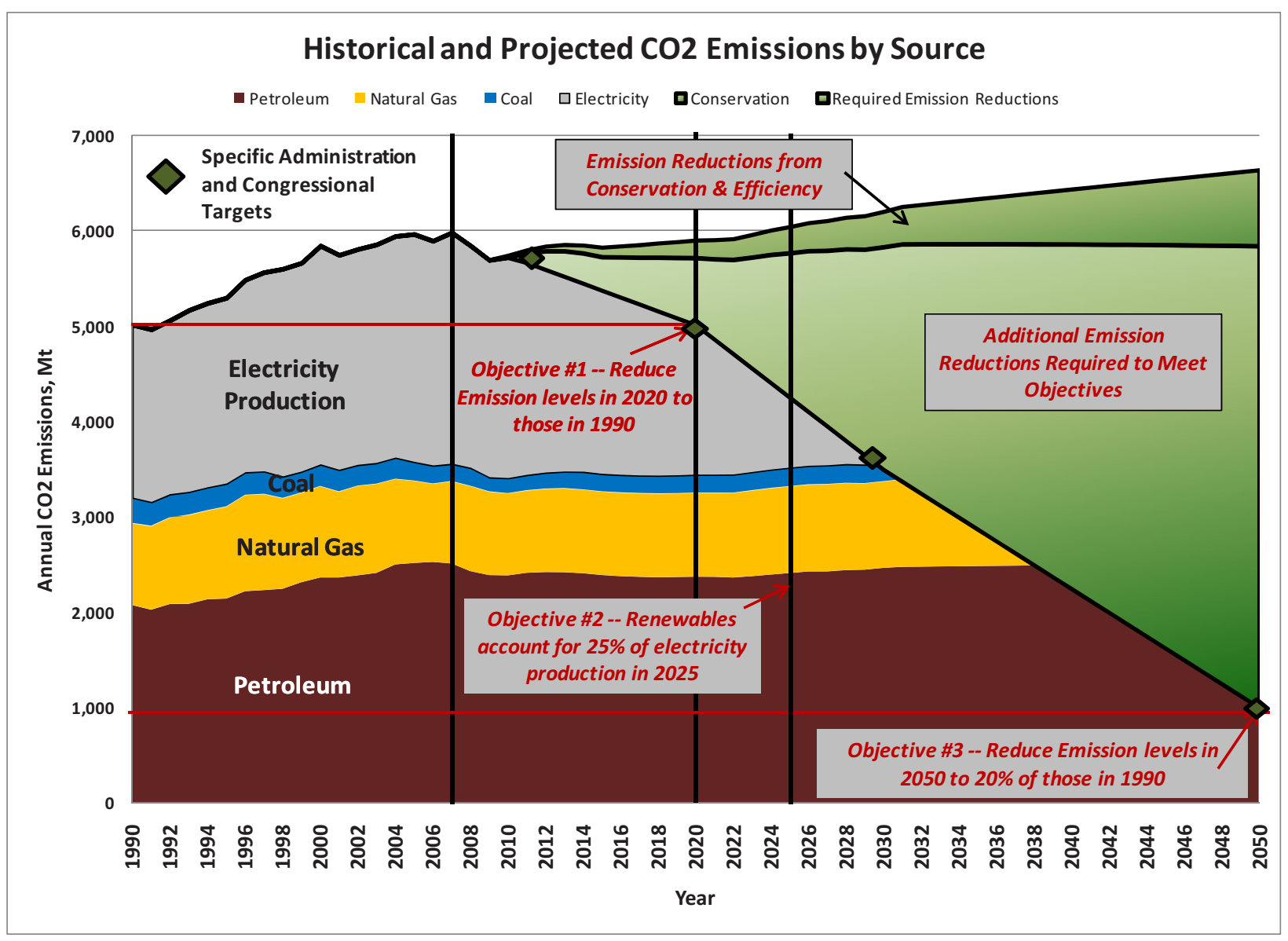

Figure 4-1. Emissions reductions from conservation and efficiency.

\subsection{Transportation}

The initiatives assumed to be viable in the transportation component address both energy security and $\mathrm{CO}_{2}$ emissions by reducing the projected demand for gasoline and diesel fuels, substituting domestically produced synthetic and biofuels for imports and increasing the use of lower emitting fuels and vehicles. These initiatives include several recommended governmental programs to meet these objectives as follows:

- Support commercialization of the cellulosic process for the production of ethanol or other bio-derivative fuels, (e.g., algae) in place of production using corn. Incentives should be provided to achieve sufficient alternative bio-fuel processing to double the annual rate of their production currently projected by EIA beginning in 2010. This would provide sufficient production capacity by 2050 to supply bio-fuels in E85 FLEX vehicles and for fueling hybrid electric vehicles. Extrapolation of DOE/EIA projected miles driven by light duty vehicles from 2030 (Table 60, April 2009, [AEO2009a]) to 2050 projects that Hybrid vehicles will account for $\sim 22 \%$ and E85 FLEX vehicles will account for $\sim 12 \%$ of the miles driven in 2050 . Electric vehicles will account for $\sim 3 \%$ of miles driven in 2050 .

- Provide incentives for production of FLEX vehicles capable of using E85 blends of ethanol (or equivalent) and gasoline and hybrid electric vehicles to achieve the maximum benefit from increased production of cellulosic ethanol and other bio-fuels on emissions and reductions in gasoline consumption. 
The use of the cellulosic process for production of ethanol reduces the $\mathrm{CO}_{2}$ emissions per mile in FLEX internal combustion engines (ICE) by 55\% compared with the emissions of corn based ethanol and $\sim 75 \%$ when compared with the emissions from petroleum based fuels. (see Table 4-1 [DOE 2009b]) The feedstocks used in cellulosic processing or for other bio-fuels production are more varied and do not compete with the food chain as does corn based ethanol. Land availability and management may also be facilitated by use of the cellulosic process or other bio-fuel processes because of the wider variety of viable feedstocks.

Table 4-1. Life cycle emissions by vehicle type and fuel.

\begin{tabular}{|c|c|c|c|c|c|}
\hline \multirow[b]{3}{*}{ Fuel Type } & \multicolumn{5}{|c|}{ Vehicle Type, $\mathrm{gCO}_{2} \mathrm{eq} / \mathrm{mile}$} \\
\hline & \multirow[b]{2}{*}{ Conventional } & \multirow[b]{2}{*}{$\begin{array}{l}\text { Hybrid } \\
\text { Electric }\end{array}$} & \multicolumn{3}{|c|}{ Plug-In Hybrid Electric } \\
\hline & & & $\begin{array}{l}\text { U.S. } \\
\text { Grid }\end{array}$ & $\begin{array}{l}\text { N.E. } \\
\text { Grid }\end{array}$ & CA Grid \\
\hline \multicolumn{6}{|l|}{ Gasoline } \\
\hline E10 & 476 & 322 & 340 & 312 & 289 \\
\hline \multicolumn{6}{|l|}{ E85 } \\
\hline Corn Ethanol & 389 & 263 & 302 & 274 & 250 \\
\hline Cellulosic Ethanol & 171 & 116 & 203 & 175 & 151 \\
\hline \multicolumn{6}{|l|}{ Diesel } \\
\hline Diesel Fuel & 405 & 305 & 328 & 301 & 277 \\
\hline $\mathrm{B} 20$ & 334 & 230 & 279 & 251 & 227 \\
\hline $\begin{array}{l}\text { EIA, "Light Duty Diese } \\
\text { Comparison of Light-D } \\
\text { February } 2009\end{array}$ & $\begin{array}{l}\text { hicles: Efficiency a } \\
\text { Vehicle Greenhous }\end{array}$ & $\begin{array}{l}\text { Emissions A } \\
\text { s Emissions }\end{array}$ & $\begin{array}{l}\text { es and } \mathrm{P} \\
\text { ort \# SI }\end{array}$ & $\begin{array}{l}\mathrm{t} \text { Issue } \\
\mathrm{F}(200\end{array}$ & \\
\hline
\end{tabular}

- Provide incentives for the development of bio-diesel alternatives. The use of bio-diesel as a substitute for crude oil based diesel would reduce projected emissions in 2050 by $\sim 60 \mathrm{Mt}$.

- Provide incentives to ensure the projected growth in the number of hybrid electric vehicles (HEVs) on the road assumed by the DOE-EIA.

The increase in the number of hybrid vehicles and FLEX fueled ICE vehicles on the road combined with a supply of cellulosic ethanol or other bio-fuels production and supply will result in significant reductions in life cycle emissions ( $\sim 365 \mathrm{Mt}$ annually in 2050 , based on cellulosic ethanol when compared with corn based ethanol) and offset significant quantities of imported crude oil.

This initiative should promote increased purchase of both HEVs and plug-in hybrids. As shown in Table 4-1, however, the improvement in emission rates for plug-in hybrids currently falls below that of HEVs when cellulosic ethanol is used as an alternative fuel. This is because of the large percentage of the electricity on the U.S. grid currently supplied by coal and natural gas. Over time, however, this will change because it will be necessary to transition the electric grid to lower emitting sources of energy to reach the emission reduction goals cited previously. The reductions in emissions credited for plug-in hybrids will increase as the grid is converted to sources that do not emit GHGs. This effect has not been considered herein.

Figure 4-2 summarizes the emissions avoided by substituting cellulosic for corn based ethanol in FLEX and Hybrid vehicles and Bio-Diesel for standard diesel. It has been assumed that the use of cellulosic ethanol and bio-diesel would apply only to the increase in miles driven by hybrid, FLEX vehicles and diesel vehicles projected by EIA from 2009 through 2050. 


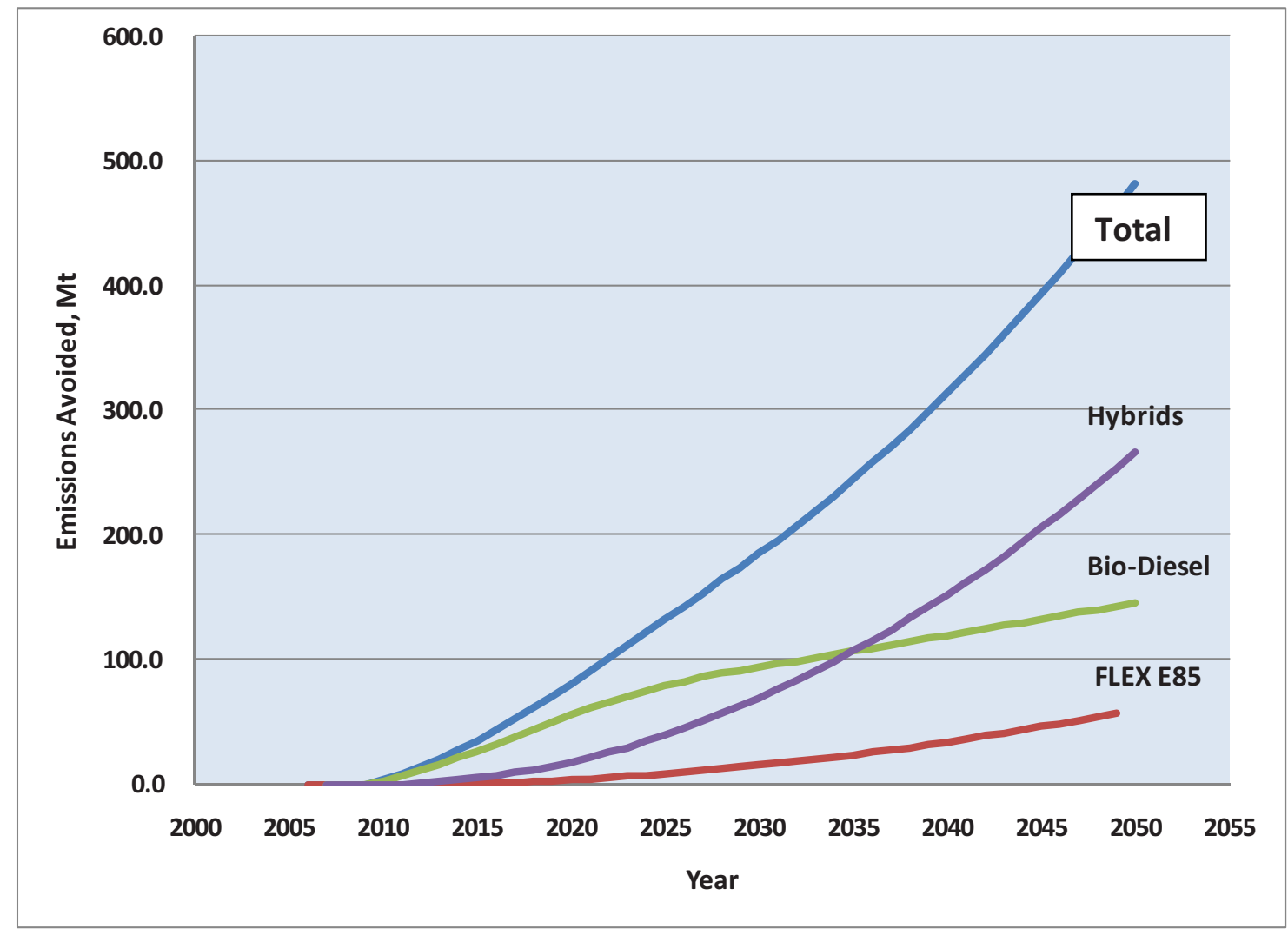

Figure 4-2. Emissions avoided by substituting cellulosic ethanol for corn ethanol and biodiesel for conventional diesel.

- Implement the increase in fuel mileage and tailpipe emission standards for vehicle Model Years (MY) 2012 - 2016 proposed by the National Highway Transportation Safety Administration [NHTSA 2009a] and the Environmental Protection Agency [EPA2009d] in response to the Administration National Fuel Efficiency Policy [ADMIN2009b]. These would increase the average new car fleet mileage standard for internal combustion engines (ICE) to $35.5 \mathrm{mpg}$ by 2016 . This results in an average increase in mileage over these model years of 4.3\% per annum. [NHTSA 2009a] The EPA has joined with the NHTSA to add a further initiative to apply the California tailpipe emission standards nationwide to MY2012-2016 automobiles. The EPA estimates that the combined effect of these emission standards with the revised CAFÉ standards would result in a reduction of $325 \mathrm{Mt}$ of emissions in 2030 and $500 \mathrm{Mt}$ in 2050. [EPA 2009c] The total emission reductions projected for these initiatives is shown in Figure 4-3. The inflection point at 2030 results from reaching the full effect of the new mileage standards. It is the point at which all cars on the road are operating at the new standard.

- The total avoided emissions per annum as a result of the sum of these initiatives is shown in Figure 4-4. As shown 1,000 Mt of emissions would be avoided in 2050.

- These initiatives would also result in significant reductions in the consumption of gasoline and conventional diesel fuel. In [DEIS, EPA 2009c] the EPA projects that the new NHTSA CAFÉ standards and the EPA proposed reduced tailpipe emission standards would result in the fuel savings and emission reductions shown in Table 4-2 (billions of gallons) compared with consumption anticipated if no action were taken. 


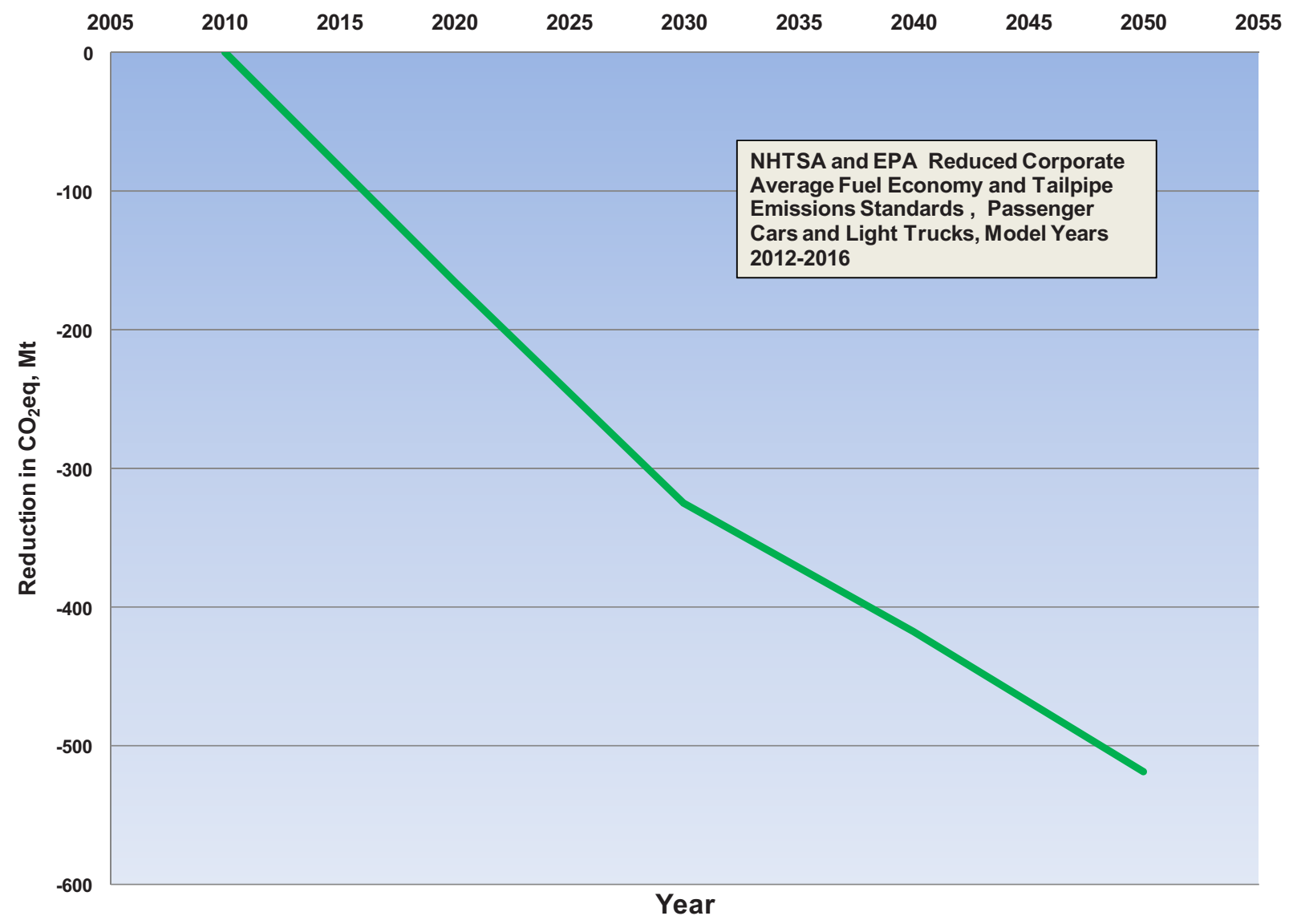

Figure 4-3. Annual emission reductions achieved from increased mileage standards.

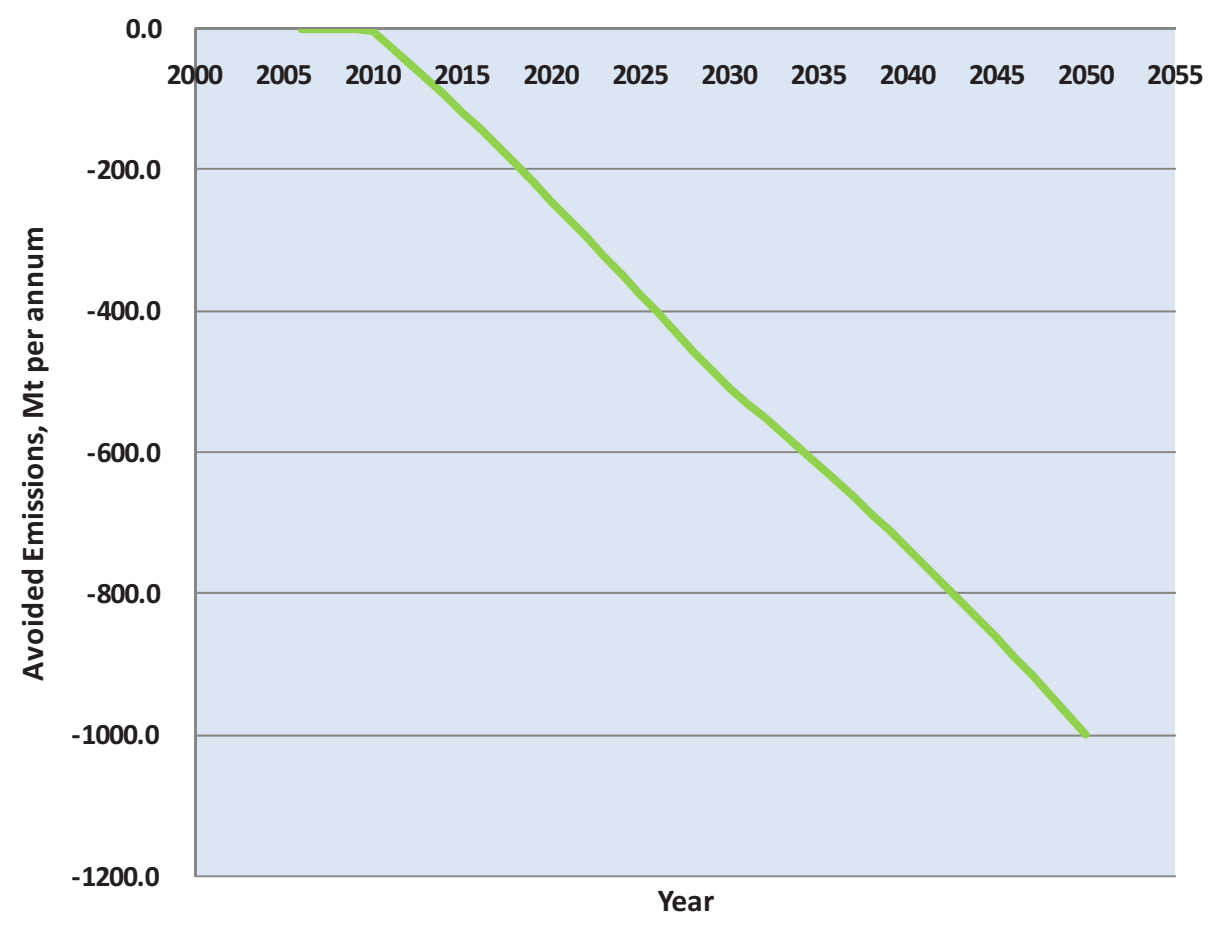

Figure 4-4. Total avoided emissions from transportation initiatives. 
Table 4-2. Projected fuel savings for proposed 2012-2016 MY CAFÉ standards.

\begin{tabular}{|c|c|c|c|}
\hline $\begin{array}{c}\text { Calendar } \\
\text { Year }\end{array}$ & $\begin{array}{c}\text { Annual GHG Reduction (CO } \mathbf{2} \text { EQ } \\
\text { Mt) }\end{array}$ & $\begin{array}{c}\text { Fuel Savings (Million Barrels Per } \\
\text { Day of Gasoline Equivalent) }\end{array}$ & $\begin{array}{c}\text { Annual Fuel Savings (Billion } \\
\text { Gallons of Gasoline Equivalent) }\end{array}$ \\
\hline 2020 & 165.2 & 0.9 & 13.4 \\
\hline 2030 & 324.6 & 1.7 & 26.2 \\
\hline 2040 & 417.5 & 2.2 & 33.9 \\
\hline 2050 & 518.5 & 2.8 & 42.6 \\
\hline \multicolumn{2}{|c|}{ Table 5.1 -- Impacts of Proposed Program on GHG Emissions and Fuel Savings [EPA DEIS 2009] } \\
\hline
\end{tabular}

[AEO 2010, Table 11] projects the consumption of ethanol, gasoline and diesel through 2035. Figure 4-5 shows the breakdown of the consumption of liquid fuels by sector and by the type of fuel for 2009 and projected for 2030 and 2050. The 2050 data was projected by a linear extrapolation of the rate of change of EIA projections over the period 2030-2035.

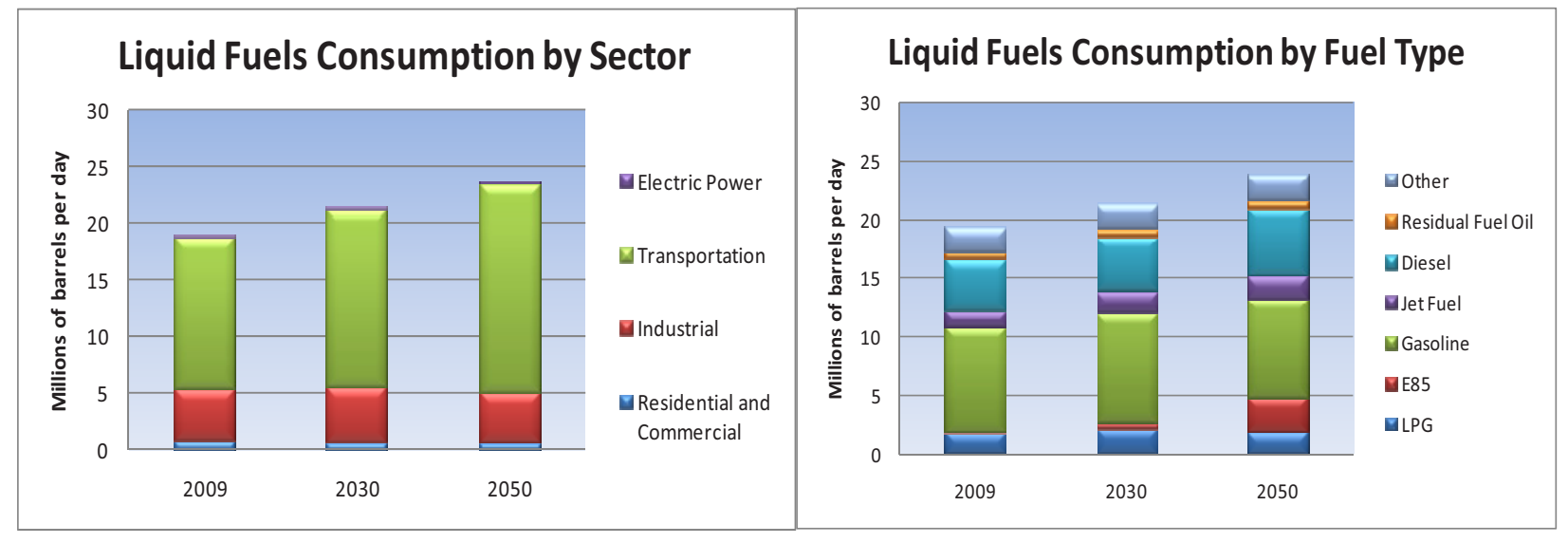

Figure 4-5. Liquid fuel consumption by sector and fuel type. [Table 11, Early Release of AEO 2010]

These projections indicate that gasoline consumption declines slightly over this 40 year period ( $\sim 380$ million gallons per day in 2009 to $\sim 350$ million gallons per day in 2050) even though the total consumption of liquid fuels in the transportation sector is projected to rise. This is due to the projected increase in ethanol consumption (in the form of E85) over this period (50 thousand gallons per day of E85 in 2009 to $~ 128$ million gallons per day of E85 in 2050 or $\sim 108$ million gallons of ethanol). Since ethanol has about $70 \%$ the energy content of gasoline [GREET2007] this represents an offset of $\sim 76$ million gallons per day of gasoline consumption in 2050 [ $128 \times 0.85 \times 0.7=76$ or 27.8 billion gallons per year]. This significant growth in ethanol consumption provides additional incentive for developing alternative methods for ethanol production such as cellulosic processes or developing equivalent bio-fuels such as algae based fuels, as substitutes for corn based ethanol. This is judged to be necessary to improve life cycle emissions of ethanol or other alternative fuels and to reduce the impact that increasing use of corn for ethanol production would have on the food chain.

Diesel consumption is also projected to increase over this period ( 143 million gallons per day in 2009 to 230 million gallons per day in 2050). Successful development of large scale production of Bio-Diesel could offset this large increase in conventional diesel consumption thereby reducing the demand for crude oil. As shown in the preceding discussion the use of bio-diesel would also result in significant reduction in emissions. 
Table 4-3 summarizes the total reduction in gasoline and diesel consumption that could be affected by these initiatives and the new NHTSA CAFÉ standards. This table also presents these reductions in gasoline and conventional diesel consumption in terms of an equivalent reduction in crude oil consumption.

Table 4-3. Impact of transportation sector emission reduction initiatives on gasoline and crude oil consumption in 2050.

\begin{tabular}{|c|c|c|}
\hline \multicolumn{3}{|c|}{$\begin{array}{l}\text { Gasoline and Conventional Diesel Consumption Reductions in } 2050 \text { due to use of Cellulosic Ethanol in } \\
\text { Flex and HEVs, Bio-Diesel Development and New CAFÉ Standards }\end{array}$} \\
\hline $\begin{array}{l}\text { Gasoline savings from full realization of the Proposed NHTSA CAFÉ } \\
\text { and EPA tailpipe emissions standards }\end{array}$ & 42.6 & Billion gallons \\
\hline $\begin{array}{l}\text { Gasoline Savings from burning of E } 85 \text { in FLEX and hybrid vehicles } \\
\text { ( } 128 \text { million gallons per day at } 70 \% \text { of the energy content of } \\
\text { gasoline.) }\end{array}$ & 27.8 & Billion gallons \\
\hline Total gasoline savings & 70.4 & Billion gallons \\
\hline $\begin{array}{l}\text { Potential conventional diesel offset of increase in diesel consumption } \\
\text { with bio-diesel ( } \sim 87 \text { million gallons per day) }\end{array}$ & 29.3 & Billion gallons \\
\hline Total gasoline and diesel reduction & 99.7 & Billion gallons \\
\hline BPD of gasoline and diesel saved & 6.5 & Million barrels/ day \\
\hline
\end{tabular}

The savings in gasoline and diesel consumption projected for 2050 is $\sim 50 \%$ of the average consumption of gasoline and conventional diesel per day in the United States in 2009 [12.42 million bpd, AEO 2010, Table 11]. Considering that in 2009 the United States imported over 58\% of its consumed crude oil $(9,150,000 \mathrm{BPD})$ and a large percentage of that goes into gasoline and conventional diesel production (67\% of each barrel of crude oil) this reduction in gasoline and conventional diesel consumption would have a significant impact on reducing reliance on imported oil.

Figure 4-6 shows the net impact of the Conservation \& Efficiency and the Transportation initiatives on the reductions in emissions necessary to meet Administration and Congressional objectives. The next section will address how the balance of the emissions reduction can be met to meet Objective \#1 in 2020 and the actions necessary to meet Objective \#2 -- renewable energy supplying $25 \%$ of electricity production in 2025 .

The next section discusses the elements of electricity production in the United States that are adapted to meet the specific targets for emissions reductions in 2020 and 2050.

\subsection{Electricity Production}

Electricity production accounts for $40 \%$ of the total emissions associated with energy production and consumption. The sources of these emissions are consolidated in coal and natural gas power stations with $\sim 84 \%$ of the emissions coming from coal fired plants [AEO2009a]. These two sources of emissions also account for about $70 \%$ of the electricity production annually [AEO2009a]. The other $30 \%$ comes from sources that emit no or very little GHGs; nuclear at $20 \%$ of total production and renewables including hydro-electric at $\sim 10 \%$ of total production being the more prevalent sources [AEO2009c, AEO2009d]. An effective strategy for reducing emissions in this sector must address (1) improved efficiency in consumption of electricity, (2) more emphasis on conservation to reduce electricity consumption, and (3) substituting non-GHG sources of electricity, (e.g., nuclear, renewable sources, clean coal) for coal and natural gas sources of electricity over the next four decades. 


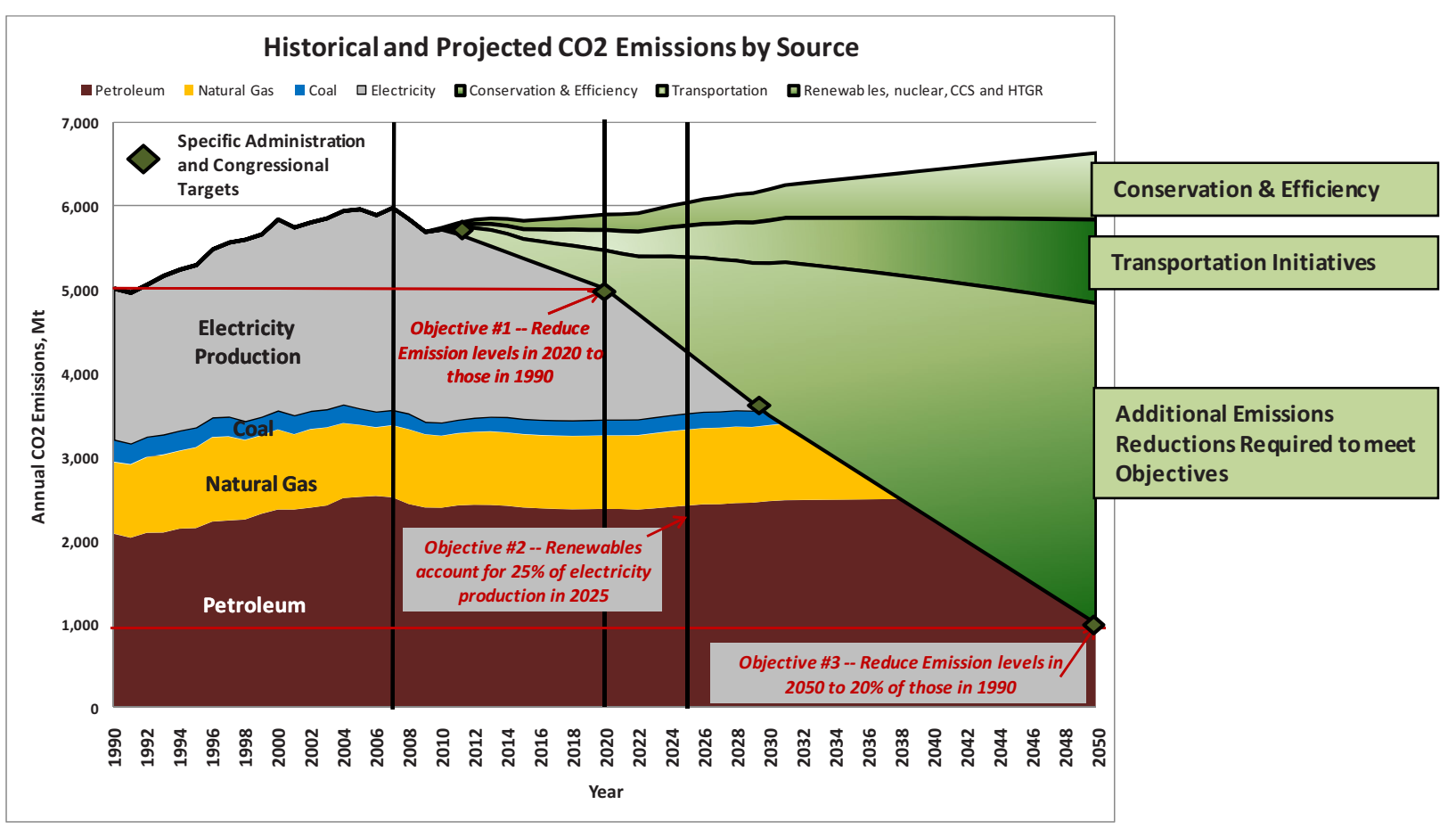

Figure 4-6. Net effect of conservation and efficiency and transportation initiatives on meeting the administration and Congressional objectives for emissions reductions.

As noted previously the $0.28 \%$ reduction in the annual growth rate of energy consumption assumed to be achievable through conservation and efficiency improvements includes reduction in electricity demand over the analysis period.

In 2008, hydro-electric accounted for about $7 \%$ of the renewable power production of electricity [AEO2009a, DOE2007]. Because most viable sites have been taken, hydro-electric production is not projected to increase materially in the future [DOE2007]. EIA projections for growth of renewable supply of electricity focus on wind as the primary growth area with solar, biomass and geothermal participating at lower rates. However, the growth rate in all renewable sources is projected at only $3.2 \%$ annually over the next 20 years [AEO2009c, AEO2009d]. This results in renewable producing $\sim 16 \%$ of total electricity production in 2030 including hydro-electric. This does not keep pace with current projections for increasing demand for electricity over the next 20 years. The projections for the growth of nuclear power are even lower $(<0.5 \%$ annually) and result in a reduction to $\sim 18 \%$ of the total production in 2030 [AEO2009a]. Meeting the demand for increasing electricity production is assumed by the EIA to be through modest annual growth rates in coal and natural gas production [AEO2009a].

Clearly these growth rates of the nonemitting sources of electricity will not result in the emissions reductions needed to meet Administration and Congressional objectives. It also does not meet the objective of renewables accounting for $25 \%$ of electricity production in 2025 . Major changes in the mix of technologies used for production of electricity are required to meet both objectives. These will include increased growth rates in renewable and nuclear power production and the introduction of clean coal power plants using carbon capture and sequestration. 
Table 4-4 summarizes the pertinent characteristics of the nonemitting sources of electricity generation that are considered herein to replace coal and natural gas plants to meet emission reduction objectives. The $\mathrm{CO}_{2}$ offset numbers and capacity factors for electricity production (in billions of kilowatt hour electric, BKwhe) are based on historical and projected EIA data on emissions and electricity production for coal and natural gas plants [AEO2009a]. They are consistent with the attributes described in Table 45 .

Table 4-4. Characteristics of nonemitting sources of electricity production.

\begin{tabular}{|c|c|c|c|c|c|c|}
\hline \multirow[b]{2}{*}{ Source } & \multirow[b]{2}{*}{$\begin{array}{c}\text { Thermal } \\
\text { Rating, } \\
\text { Mwt }\end{array}$} & \multirow[b]{2}{*}{$\begin{array}{c}\text { Elec } \\
\text { Rating, } \\
\text { Mwe }\end{array}$} & \multirow[b]{2}{*}{$\begin{array}{c}\text { Cap } \\
\text { Factor }\end{array}$} & \multicolumn{3}{|c|}{ Annual } \\
\hline & & & & $\begin{array}{l}\text { Total Annual } \\
\text { Electricity } \\
\text { Production per } \\
\text { Unit, } \\
\text { BKWhe }\end{array}$ & $\begin{array}{c}\text { Mt of } \mathrm{CO}_{2} \\
\text { Emissions } \\
\text { Avoided by } \\
\text { Offsetting } \\
\text { Coal Usage } \\
\end{array}$ & $\begin{array}{c}\text { Mt of } \mathrm{CO}_{2} \\
\text { Emissions } \\
\text { Avoided by } \\
\text { Offsetting } \\
\text { NG Usage } \\
\end{array}$ \\
\hline Wind $^{\mathrm{c}}$ & N/A & 5 & 0.4 & 0.013 & 0.012 & 0.005 \\
\hline $\mathrm{LWR}^{\mathrm{d}}$ & 3,600 & 1,200 & 0.92 & 9.650 & 9.352 & 3.843 \\
\hline HTGR $^{\mathrm{e}}$ & 600 & 252 & 0.92 & 2.027 & 1.964 & 0.807 \\
\hline Coal CCS & 2,408 & 800 & 0.74 & 5.158 & 4.999 & 2.054 \\
\hline
\end{tabular}

Table 4-5. Characteristics of conventional coal and natural gas plants.

\begin{tabular}{|l|c|c|}
\hline \multicolumn{1}{|c|}{ Attribute } & Average Net Efficiency & Lbs CO $_{2}$ emitted/MMBtu \\
\hline Coal plants & $33.3 \%$ & 213 \\
\hline Natural Gas plants & $44.6 \%$ & 117 \\
\hline
\end{tabular}

Table 4-6 is the source of the capacity factors used for this analysis:

Table 4-6. Summary of capacity factors for electricity production.

\begin{tabular}{|l|c|}
\hline Nuclear & $91.8 \%$ \\
\hline Coal & $73.6 \%$ \\
\hline Other Renewables & $42.0 \%$ g \\
\hline Hydroelectric & $40.1 \%$ \\
\hline Petroleum & $36.3 \%$ \\
\hline Natural Gas/Other Types & $13.4 \%$ \\
\hline $\begin{array}{l}\text { Sources: Energy Information Administration, Form EIA-860, "Annual Electric Generator } \\
\text { Report;" Form EIA-923, "Power Plant Operations Report." }\end{array}$ \\
\hline
\end{tabular}

c. For the purposes of this analysis it is assumed that deployment of wind turbines will predominate the application of renewables and that the deployment will include $90 \%$ land based and $10 \%$ offshore based.

d. Nuclear light water reactor; the capacity factor is representative of the current fleet of 104 reactors.

e. High Temperature Gas Reactor; the capacity factor is assumed to be the same as the LWR.

f. Coal plant with carbon capture and sequestration; the capacity factor is assumed to be the same as current coal plants.

g. This has been the historical capacity factor for natural gas plants because they have been traditionally used in peaking service; not base loaded. If governmental policies result in costs for carbon emissions the use of natural gas plants for base loaded service will increase. Under those circumstances a capacity factor of $85 \%$ is assumed. [King 2008] 
Note that the capacity factor for Other Renewables includes the composite for wind, solar, wood and wood products, biomass and geothermal. The capacity factors for the individual components vary considerably. The average capacity factor used for analysis of renewable production is $40 \%$. This is the capacity factor cited by AEO2009 for the 2008 mix of renewable energy sources.

\subsection{Renewable Electricity Production}

\subsubsection{Renewable Production to 2025}

The growth rate of renewable capacity on the grid will need to increase significantly to meet the Administration objectives for renewable production accounting for $25 \%$ of total production, including hydro-electric, by 2025. As shown above in the discussion on Objective \#2, this requires an increase of 535 billion kilowatt hours of renewable production over that projected by [, AEO2009c, AEO2009d] for 2025.

For the purposes of this analysis the following will be assumed:

- The current EIA projected growth rate for renewable production over the period 2010 through 2025 ( $\sim 3.4 \%$ annually) will need to almost double to $\sim 6.5 \%$ annually to achieve the objective of $25 \%$ of total production by renewable in 2025 (See Figure 4-7). As shown in the figure the rate of increase in renewable generation predicted by the EIA over the next two years would need to be sustained through 2025 to meet the Administration Objective \#2. It is understood that the Congressional Bills have provisions that make reductions in consumption equivalent to an increase in renewable production. The EPA assessment of HR2454 [EPA2009a, EPA2009b] predicts a very modest increase in renewable electricity production over this period because of the predictions in reduced consumption described in a preceding section. For the purposes of the analyses herein, however, both reductions in consumption \& efficiency and increases in renewable electricity production in accordance with Objective \#2 will be accounted for.

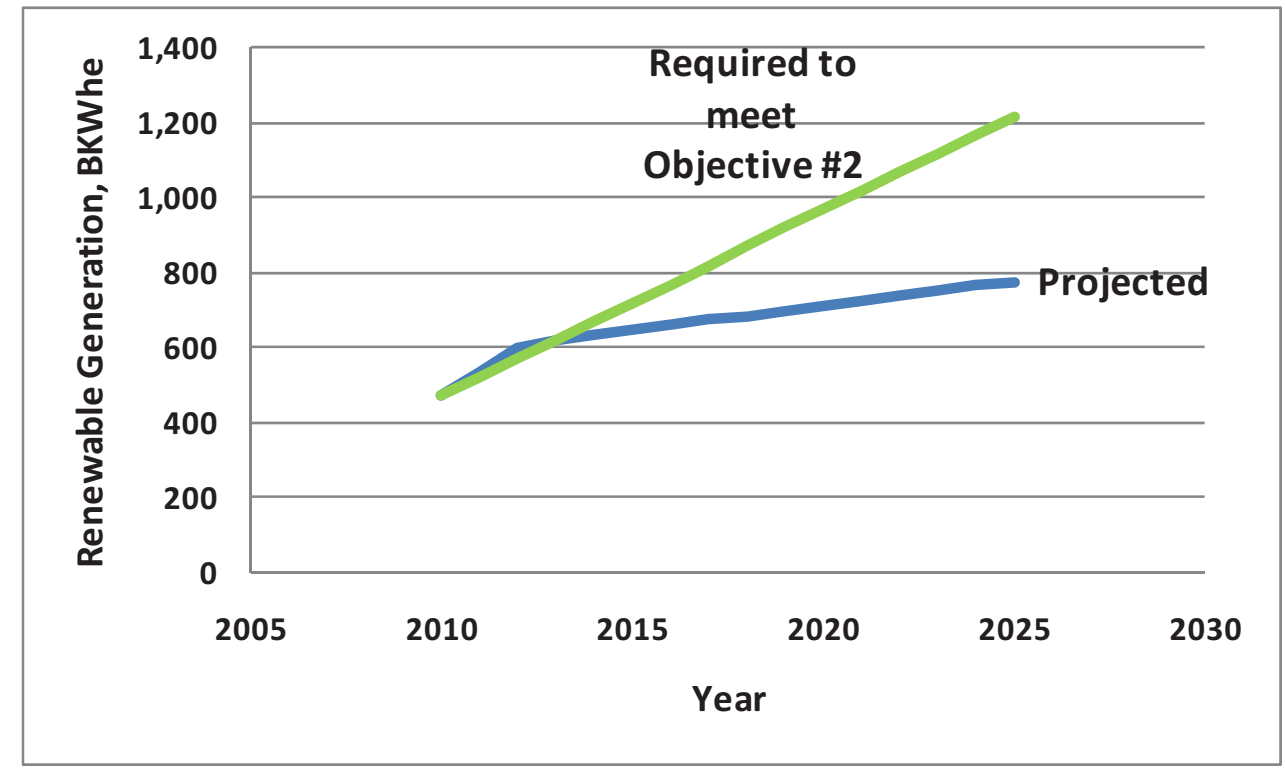

Figure 4-7. Growth in renewable electricity production required to meet Objective \#2 compared with AEO2009a projections of renewable generation growth. 
Table 4-7 summarizes the share of renewable electricity production predicted by EIA in 2010 and 2025. As shown in the table, EIA predicts that renewable electricity generation includes hydro, wind and other technologies such as solar, biomass, geothermal. In this mix wind and biomass are predicted to provide a significant share of generation in 2025 with biomass predicted to have approximately the same share of generation as wind. The other technologies other than hydro do not have a significant share. It is noted that the specific generation by hydro is not predicted to increase significantly 2010 to 2025 so its share of generation in 2025 is reduced. This is attributed to a lack of new technically and economically viable sites for new hydro plants.

From an electricity generation perspective biomass is not currently a large source. Biomass is described as an emissions neutral source of energy for electricity production. However, recent evaluations [Searchinger2009] show that the premise that biomass is emissions neutral may not be correct.

Table 4-7. Summary of renewable electricity generation by technology in 2010 and 2025.

\begin{tabular}{|l|c|c|c|c|}
\hline \multirow{2}{*}{ Renewable Generation Technology } & \multicolumn{2}{c|}{2010} & \multicolumn{2}{c|}{2025} \\
\cline { 2 - 5 } & $\begin{array}{c}\text { Generation } \\
\text { BKWhe }\end{array}$ & $\begin{array}{c}\text { Generation } \\
\text { BKWhe }\end{array}$ & \% of Total \\
\hline Conventional Hydropower & 270 & $57.8 \%$ & 299 & $38.8 \%$ \\
\hline Geothermal & 18 & $3.8 \%$ & 22 & $2.8 \%$ \\
\hline Biogenic Municipal Waste & 22 & $4.8 \%$ & 24 & $3.2 \%$ \\
\hline Wood and Other Biomass & 41 & $8.8 \%$ & 197 & $25.5 \%$ \\
\hline Solar Thermal & 0.99 & $0.2 \%$ & 2 & $0.3 \%$ \\
\hline Solar Photovoltaic 5/ & 3 & $0.7 \%$ & 19 & $2.5 \%$ \\
\hline Wind & 112 & $24.0 \%$ & 207 & $26.8 \%$ \\
\hline Offshore Wind & 0.00 & $0.0 \%$ & 0.75 & $0.1 \%$ \\
\hline Total & 468 & & 771 & \\
\hline [AEO2009d Table 10.1 Renewable Energy Generation by Fuel] & & & \\
\hline
\end{tabular}

It is not possible to identify with any certainty what strategy or technology will prevail in adding renewable generation. However, the majority of renewable additions over the last decade in the United States have been in wind turbines. More information is also currently available on the capacity factors, size and costs for construction and operation of wind turbines than for other renewables. As noted there is also uncertainty in the environmental benefit of biomass generation. Accordingly, for the purposes of the analyses herein, the increase in renewable generation will be accounted in terms of additions of wind turbines. Use of wind as a surrogate for renewable energy growth herein is used simply to illustrate the magnitude of the effort required in this area to support meeting objectives.

It is assumed that technical advancements in the design of wind turbines will result in an average power rating per turbine of $5 \mathrm{MWe}$. The current average size of commercial wind turbines is in the range of 1 to 2 MWe with 3 MWe turbines likely available in the next generation. The actual size of the wind turbines that will be available over the next 15 years cannot be predicted with reasonable certainty. The only use of this assumed size of turbines is in assessing how many would be required to meet the objectives. Clearly the actual number of turbines and their size will be diverse over the next four decades. This does not affect the conclusions, however, on the total capacity additions that will be required to meet the emissions reductions objectives no matter what the technology.

For emission offset purposes it will be assumed that the increase in renewable generation offsets the equivalent amount of generation from conventional coal plants rather than from natural gas fueled plants. 
This is the most likely outcome since experience has shown that some cycleable backup capacity is required on the grid to accommodate the fluctuating nature of renewable generation, particularly wind turbine generation [Parsons2008, IEA2009, Benitez2007, FERC2005]. Natural gas combustion turbines are better suited for this purpose than coal plants. The current prices for natural gas also make them competitive with coal plants [DOE2009d].

The average capacity factor used for analysis of renewable production is $40 \%$. This is the capacity factor cited by AEO2009 for the 2008 mix of renewable energy sources, [Table 4, AEO2009c].

At this average capacity factor the required growth rate requires the addition of about 125 Gwe of renewable capacity over the next 15 years or $\sim 8,300$ Mwe per year above the $65 \%$ increase in renewable capacity projected by DOE-EIA (771 BKWhe in 2025 versus 468 BKWhe renewable production in 2010; an increase of $90 \mathrm{GWe}$ capacity at a capacity factor of $40 \%$ ). At $5 \mathrm{MWe}$ per turbine this is equivalent to adding 25,000 wind turbines over the next 15 years. About 8,900 MWe of wind turbine capacity was added in 2008 due to favorable governmental tax and production credits. The projections for 2009 are lower due to expiration of these credits. Some form of government incentives will be necessary to achieve the growth rates in all forms of renewable power needed.

This increase in renewable power on the grid results in avoiding $426 \mathrm{Mt}$ of $\mathrm{CO}_{2}$ emissions annually in 2025; assuming the renewable power offsets the equivalent amount of coal based power.

\subsubsection{Renewable Production Through 2050}

It is assumed that renewable generation is maintained at $25 \%$ of total generation through the end of the analyses in 2050.

It is assumed that the percentage of renewable generation on the grid is limited to this value because of the uncertainty in how much penetration of renewable energy, particularly wind turbines, is acceptable to ensure grid stability and reliability and is economically viable. The latter is of concern because of the relative low capacity factor achieved with wind turbines in certain areas of the country.

NREL/CP-500-43540 [Parsons2008] summarizes the results of 18 case studies on the costs of wind integration internationally under a National Renewable Energy Laboratory (NREL) contract. This summary concluded, in part, that:

"The capacity value of wind power can be up to $40 \%$ of installed capacity if wind power production at the times of high load is high, and down to $5 \%$ in higher penetrations and if local wind characteristics correlate negatively with the system load profile." In other words the viability of wind as an economic and reliable source of power is very sensitive to location and power demand profile.

"Integration costs of wind power need to be compared to something meaningful, like production costs or market value of wind power, or integration costs of other production forms. There is also benefit when adding wind power to power systems; it reduces the total operating costs and emissions as wind replaces fossil fuels." [Note that the latter part of this statement on operating costs is contradictory to a previous conclusion that "From the investigated studies, system operating cost increases amounted to about 1 to 4 euros/Mwh"]. The study also concluded that "the cost of grid reinforcements due to wind power is dependent on where the wind power plants are located relative to load and grid infrastructure. The grid reinforcement costs from investigated studies varied from 35 to 160 euros/Kw [of installed capacity]." 
Finally, the study concluded that "For high penetration levels of wind power, optimization of the integrated system should be explored. Modifications to system configuration and operational practices to accommodate high wind penetration may be required. For high penetration, there will be need for increased generation flexibility, transmission to neighboring areas, demand side management, or storage, (e.g., pumped hydro, thermal, or batteries of electric cars)."

Benitez, et.al. [Benitez2007] studied the addition of wind power at two different sites to the Alberta, Canada grid and concluded:

When wind power is added to an electrical grid consisting of thermal and hydropower plants, it increases system variability and results in a need for additional peak-load, gas-fired generators. [This cost needs to be included in the evaluation of the economics of the application.]

There are several studies on the combination of compressed air storage with wind turbines to provide a means for smoothing out production. These use a combination of wind power to compress and store air which is then released and heated in a conventional gas turbine to produce electrical power. It appears that the benefit of this arrangement is a lessening of the natural gas required for the combustion turbine, reducing emissions and potentially reducing costs, depending on the cost of natural gas [IOWA 2006, WIKI2010].

The evaluation performed in this paper does not attempt to address these issues or quantify the costs or uncertainties associated with use of renewable for high percentages of electricity production

Table 4-8 summarizes the build out required in renewable energy supplies over the next four decades and the impact on emission reductions and the percent of electricity production by renewable required to meet the Objective \#2 that $25 \%$ of total electricity production in 2025 be by renewable technologies. Figure 4-8 shows the annual reductions in emissions for this build out.

The required increase in the on-line renewable power generation is significant. Whether this rate of growth is achievable or desirable, particularly for the higher penetration considering the potential for unsuitable influence on the electric grid and the cost impact on electrical power, depends on the overall strategy, incentives and provisions of the government program for emissions reductions. Such growth in the renewable energy penetration would require significant increases in the industries supporting equipment manufacture, installation and operation and in the transmissions and grid control systems. The latter will be necessary to move the power from the locations best suited for production, (e.g., high and sustained wind locations) to the consumers. The analyses herein have not attempted to scope the costs of these electric power transmission and distribution infrastructure upgrades.

Table 4-8. Summary of the renewable initiative.

\begin{tabular}{|l|c|c|c|c|c|}
\hline \multirow{2}{*}{ Energy Initiative } & \multicolumn{5}{c|}{ Renewable Initiative } \\
\cline { 2 - 7 } & $\mathbf{2 0 1 0}$ & $\mathbf{2 0 2 0}$ & $\mathbf{2 0 2 5}$ & $\mathbf{2 0 3 0}$ & $\mathbf{2 0 5 0}$ \\
\hline EIA Projected Generation, BKWhe & 468 & 708 & 771 & 797 & 903 \\
\hline Delta Generation, BKWhe & 0 & 255 & 439 & 466 & 572 \\
\hline Revised Production, BKWhe & 468 & 963 & 1210 & 1264 & 1474 \\
\hline$\%$ of Total Production & $11.2 \%$ & $21.1 \%$ & $25.0 \%$ & $25.0 \%$ & $25.0 \%$ \\
\hline Delta Capacity, Gwe & 0 & 73 & 125 & 133 & 163 \\
\hline Number of Plants (5 Mwe/plant) & 0 & 14,564 & 25,069 & 26,612 & 32,623 \\
\hline Delta Avoided Emissions, Mt & 0 & 247 & 426 & 452 & 554 \\
\hline \multicolumn{2}{|c|}{ EIA Data and Projections Table 85 AEO2009a April update extrapolated to 2050 using linear correlations } \\
\hline
\end{tabular}




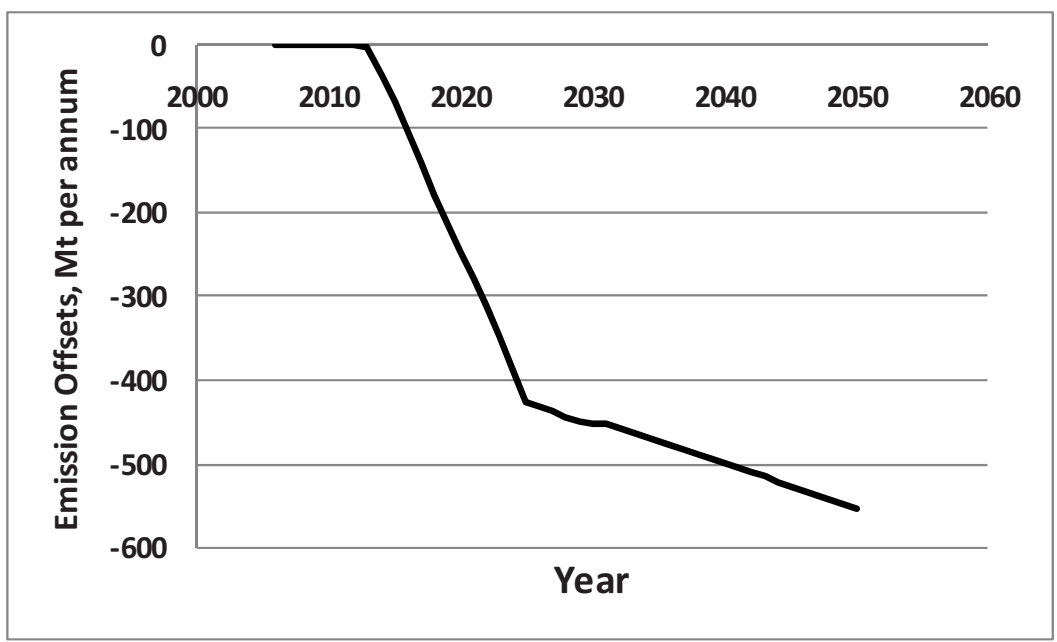

Figure 4-8. Emissions avoided by replacing coal generated electricity with renewable technologies.

The combination of Conservation \& Efficiency, Transportation initiatives and the Renewable scenarios through 2050 result in subtotal reductions in annual emission rates as shown in Table 4-9.

Table 4-9. Total avoided annual emissions in 2050 for transportation and renewable sectors.

\begin{tabular}{|l|c|c|c|}
\hline \multicolumn{1}{|c|}{ Sector } & $\begin{array}{c}\text { Avoided Annual } \\
\text { Emissions in 2050 }\end{array}$ & Sub Totals by Scenario & $\begin{array}{c}\text { Balance to } \\
5,640 \text { Mt Reduction }\end{array}$ \\
\hline Conservation \& Efficiency & 800 & 800 & 4,840 \\
\hline Transportation & 1000 & 1,800 & 3,840 \\
\hline Renewable Additions & 560 & 2,340 & 3,280 \\
\hline
\end{tabular}

The balance can be made up by a combination of advanced LWR nuclear plants (ALWR), High Temperature Gas Reactor (HTGR) plants and Coal plants with carbon capture and sequestration (Coal CCS) as summarized in the following sections.

Figure 4-9 shows the combined impact of Conservation \& Efficiency, the Transportation Sector initiatives and the Renewable Energy Sector initiatives as increments to achieving Objective \#1 emissions by 2020 and achieving Objective \#2 (25\% of total electricity production by renewables in 2025). Note that this figure only extends to 2025 (not to 2050) to emphasize the 2025 renewable objective.

As seen on this figure the combination of Conservation \& Efficiency, the Transportation initiatives and Renewable Energy sector initiatives are not sufficient to meet the required emission reductions of Objective \#1, reducing projected emissions in 2020 to 1990 levels. It is also not considered reasonable to increase the rates of growth in these sectors beyond the levels already assumed. The balance of the required emission reductions ( $\sim 235 \mathrm{Mt}$ in 2020) are assumed to come from increasing the growth of electric power generation using advanced light water nuclear reactor technology. 


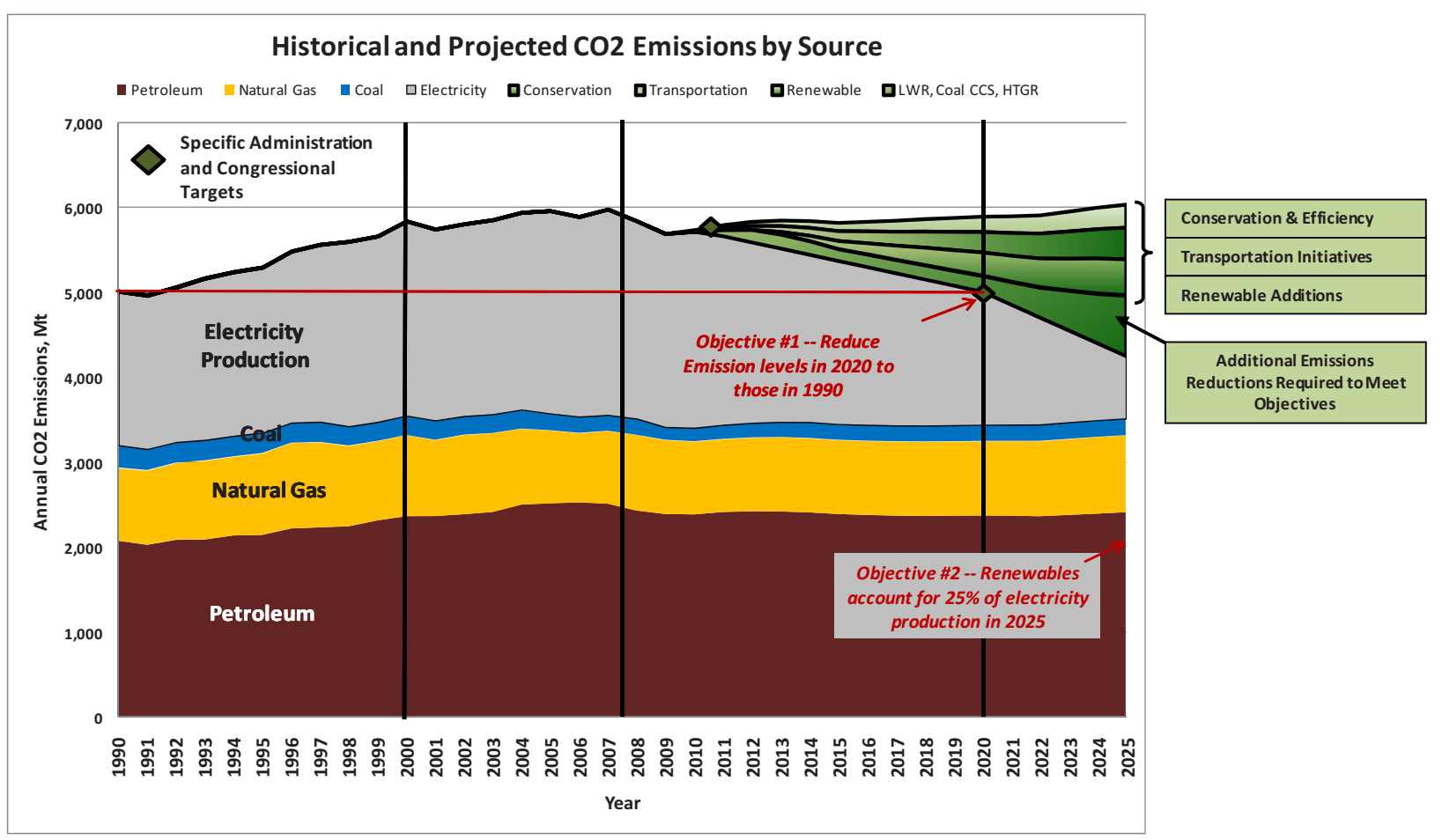

Figure 4-9. Impact of conservation, transportation and renewable initiatives on meeting emissions Objective \#1 and renewable production Objective \#2.

\subsection{Electricity Production using Nuclear Power through 2020}

Advanced nuclear plant technology is available and can begin to be deployed with construction started in 2010 or 2011 with the required incentives. The incentives require executing the licensing and financing incentives that were initiated in the government's [NP2010, EPACT2005] programs. These incentives protect the initial installations of the advanced nuclear technology from significant delays due to the licensing process, (so-called standby support) and provide financial guarantees, (e.g., loan guarantees, construction and production tax incentives) that will provide sources of financing for these projects and covering the initial startup costs. Much of the licensing for the advanced nuclear plant designs has been completed as part of the design certification process initiated in these programs. Several utilities have selected sites and designs for new installations. As of December 31, 2008 there were 31 applications for licenses by the NRC [DOE2008]. Once the licenses are granted government support will be required to initiate deployment.

To achieve the total emissions reductions of Objective \#1 an additional $235 \mathrm{Mt}$ annual emission reduction is required in 2020. Table 4-4 and Table 4-6 summarize characteristics of the several technologies that are used in the United States for the production of electricity that are used in this paper to develop the strategy for substituting non-GHG emitting sources of electricity for current GHG emitting sources, (e.g., replacing a coal based plant with wind turbines as described in the preceding section). Using the data in this table a reference advanced light water reactor (ALWR) can offset $\sim 9.4 \mathrm{Mt}$ of annual $\mathrm{CO}_{2}$ emissions from the reference coal fired plant and $\sim 3.8 \mathrm{Mt}$ from the reference natural gas plant. Assuming that the addition of nuclear capacity results in retirement of $75 \%$ of the equivalent coal production and $25 \%$ of the equivalent natural gas production, one nuclear plant will offset $\sim 8 \mathrm{Mt}$ of $\mathrm{CO}_{2}$ emissions annually. Accordingly, 30 new nuclear plants will need to be built by 2020 or $\sim 3$ per year to achieve the emissions reductions required to meet Objective \#1. 
It is judged that if the incentives summarized above are provided in 2010 by the government for the first few plants, this build out rate is reasonable. As noted there are currently 31 license applications pending for advanced nuclear plants. To also put this build rate in perspective it is informative to examine the current activity in building nuclear plants internationally. China currently has 24 LWR nuclear plants in some phase of construction and commissioning. Several nuclear power plants are being built in Russia, India and Finland. The build out rate of 30 new nuclear plants over the next ten years is, therefore, not unprecedented.

Accordingly, the balance of the deficit in emission reductions in 2020 shown in Figure 4-9 above is assumed to be made up by deployment of these additional nuclear plants over the next ten years.

\subsection{Use of Nuclear Energy in the Industrial and Commercial Sectors}

The industrial and commercial sectors burn significant quantities of gas, (e.g., natural gas) in crude oil refining, petro-chemical processes, fertilizer production, etc. and for the generation of steam, electricity and hydrogen. The combustion of gases is the primary source of the emissions from this sector and in combination with the residential sector account for $\sim 34 \%$ of energy consumption. Not only does combustion of natural gas add to the carbon footprint of the processes but the price of natural gas has fluctuated widely over the last several years adding uncertainty to the cost of the processes. Additionally, natural gas has benefit as a feedstock, (e.g., in petro-chemical processing). Using the gas as an energy source is a poor use of this limited resource.

The high temperature gas reactor (HTGR) is a non-GHG emitting alternative to the burning of natural gas and other fossil fuels in industrial and commercial processes. The DOE initiated the Next Generation Nuclear Plant Project (NGNP) in FY-06 as an outcome of the 2005 Energy Policy Act. This Project has the objective of commercializing the HTGR technology. The HTGR is a helium cooled, graphite moderated reactor that can operate at temperatures up to $950^{\circ} \mathrm{C}$. Because it operates at a much higher temperature than an LWR (typically operating temperatures of a light water reactor (LWR) are in the range of $300^{\circ} \mathrm{C}$ ) it can be used in commercial applications other than for generation of electricity; the principal application of LWRs to-date. These applications include supplying process heat and energy in the forms of steam, electricity and high temperature gas to a wide variety of industrial processes including, for example, petro-chemical and chemical processing, fertilizer production, and crude oil refining. In addition to supplying process heat and energy the HTGR can be used to produce hydrogen and oxygen which can be used in combination with steam and electricity from the HTGR plant to produce, for example, synthetic transportation fuels, chemical feedstock, ammonia, from coal and natural gas. Studies performed to the date of this writing and discussions with potential end users have investigated the characteristics of the HTGR that best fit these applications. [NGNP2007, NGNP2009] These studies have concluded that reactor module sizes in the range 200 to $600 \mathrm{MWt}$ operating in the temperature range of 700 to $800^{\circ} \mathrm{C}$ can satisfy most of the energy needs of these applications.

The following discusses assumptions on specific applications of this technology that are judged technically and economically viable for substitution of natural gas firing in Co-generation and Heat Supply processes.

\subsubsection{Supplying Process Heat and Energy to Industrial Processes}

In most applications supplying heat and energy to an industrial process multiple HTGR modules would be deployed with an average plant at a total rating of 2,000 to 2,400 MWt containing 4 to 10 modules depending on the rating of each module. These plants would be used to supply steam, electricity and hot fluids to the process. Based on the current NGNP schedule the first-of-a-kind (FOAK) commercial module could be operating in 2022. It is anticipated that multiple modules will be deployed in this initial application and, when shown to be successful, in many other similar applications. Based on 
scoping estimates it is judged that there are 150 refineries, 100 petro-chemical plants, $100+$ ammonia and ammonia derivative plants, and many other industrial plants for which the HTGR technology could be used to supply energy needs. [MPR 2008a \& b]

The HTGR technology also provides a non-GHG source of energy for extraction and processing of unconventional sources of hydrocarbons such as from the oil sands of Alberta, Canada and from Oil Shale which is prevalent in the United States and Canada. Conventional processes for extraction and processing from these sources use natural gas as the energy source with significant $\mathrm{CO}_{2}$ emissions. This is a poor use for a limited natural resource. Studies have shown that the HTGR technology is a viable substitute for natural gas firing in these applications technically and economically. Based on this work less than twenty 600 Mwt HTGR modules would be required to supply steam to Steam Assisted Gravity Drainage systems to extract 1 million barrels of bitumen per day from Canadian Oil Sands. [INL 2009b]

Figure 4-10 illustrates the potential end users of this technology and the number of plants available for use. For this study we have assumed that about 250 plants using on average four $600 \mathrm{MWth}$ modules could be deployed in the U.S. within the petrochemical, petroleum refining, fertilizer/ammonia manufacturing plants and for extraction of nonconventional hydrocarbons from oil shale. These would be used as substitutes for natural gas firing in the production of steam, electricity and heat in the form of hot gas and hydrogen. This would take place in the period 2022 through 2050; requiring the building of about 10 plants per year on average. Substituting this build out of HTGR plants for gas fired plants would avoid $\sim 835 \mathrm{Mt}$ of $\mathrm{CO}_{2}$ emissions in 2050. (Note this does not include deployment of plants in Canada for extraction and upgrading Bitumen from oil sands.)

\subsubsection{Biomass/Coal to Synthetic Liquid Fuels (BTL/CTL)}

The HTGR technology is also applicable to production of synthetic hydrocarbons from coal and biomass which can be made into transportation fuels and feedstock, (e.g., for petrochemical plants). These synthetic hydrocarbons are produced using traditional coal and biomass to synthetic fuel processes but with the HTGR supplying the energy, hydrogen and oxygen. Because the HTGR does not emit any $\mathrm{CO}_{2}$, a process optimized for use of the HTGR energy improves the efficiency of carbon transfer from the coal and biomass to the production fuels from a typical conventional plant conversion rate of $\sim 30 \%$ to over $90 \%$ resulting in essentially no carbon footprint [INL2009b]. This provides a mechanism for clean production of synthetic fuels from indigenous resources of coal and biomass reducing emissions from refining of crude oil and improving energy security by reducing the need to import crude oil. This is also a long term solution to the production of transportation fuels as the indigenous sources of crude oil are expended [INL2009c]. 
Figure 4-11 compares the life cycle emissions for transportation fuels derived from traditional refining of crude oil, from conventional coal to liquid (CTL) processes and from oil sands using traditional fossil fuel based technologies with the use of HTGR technology for extraction from oil sands and for coal to liquid processes. As shown, the HTGR technology provides significant benefits in life cycle emissions reductions for these processes. "Well to tank" emission levels using the HTGR technology are several orders of magnitude less than conventional CTL processes and conventional oil sands extractions. (Emissions from combustion of the transportation fuels are similar for conventional and coal to liquid fuels.) This use of HTGR technology in the coal to liquids process also has emission levels several factors lower than those produced by conventional production and refining of crude oil.

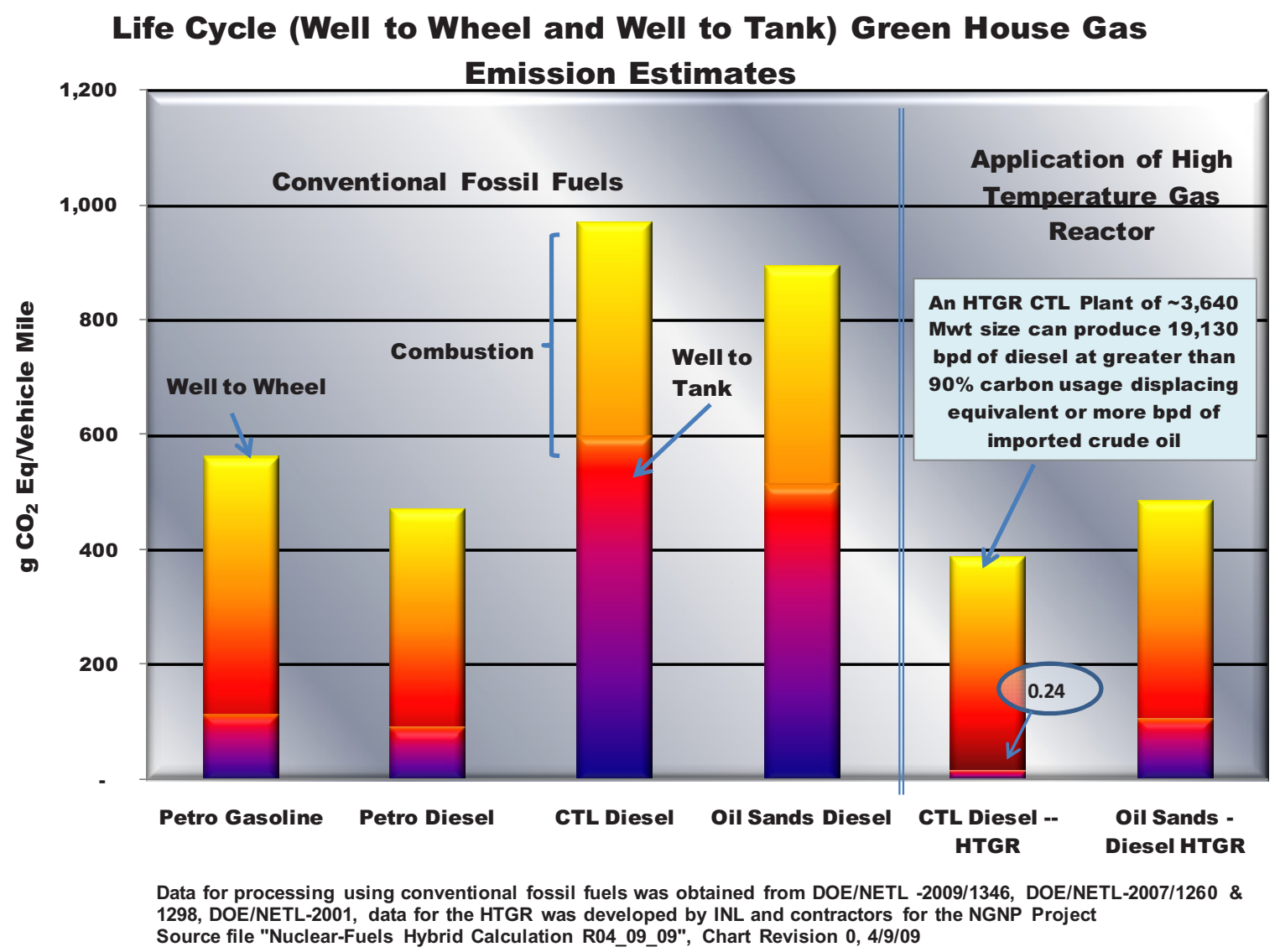

Figure 4-11. Comparison of life-cycle emissions for several processes.

At the time of this writing there is limited production of synthetic fuels from coal and biomass in the U.S although several studies by the DOE NETL [NETL2007a,b,c, NETL2008] and others [Agrawal2007, NATLACAD] have shown the potential benefit in energy security in developing this technology. For this study we are assuming that aggressive action by the government to support development of this technology would result in the building of $24-100,000$ barrels per day CTL plants ${ }^{\mathrm{h}}(\sim 22-600$ MWth HTGR modules per plant) in the 2022 - 2050 time frame; less than one plant per year on average.

Governmental action in support of this activity is desirable since, as will be shown below, this activity will not only reduce emissions but will also reduce the need to import crude oil and will utilize our most abundant form of energy, (i.e., coal) more effectively and with essentially no effect on the environment.

h. The specific characteristics of the CTL plant used in this study are based on recent INL work on applying the HTGR technology to this type of plant [INL2009b]. 


\subsubsection{Benefits of the Full Deployment of the HTGR Technology}

Table 4-10 summarizes the potential build out of HTGRs for both co-generation, oils sands recovery and BTL/CTL synthetic fuel production over the period 2022-2050 and the reductions in annual emissions in 2050 from deployment of these reactors assumed for this study. In 2050 a total of $\sim 920 \mathrm{Mt}$ of $\mathrm{CO}_{2}$ emissions are avoided per year. Note that the calculation of the reductions in $\mathrm{CO}_{2}$ emissions for deployed HTGR CTL plants was made in comparison with conventional crude oil refining. In comparison with a conventional CTL plant the reductions would be $\sim 800 \mathrm{Mt}$ per annum instead of $82 \mathrm{Mt}$ per annum.

Table 4-10. Deployment of HTGRs (all numbers are accumulative in time).

\begin{tabular}{|l|c|c|c|c|c|c|}
\hline HTGR Process Heat \& Energy & $\mathbf{2 0 1 0}$ & $\mathbf{2 0 2 0}$ & $\mathbf{2 0 2 5}$ & $\mathbf{2 0 3 0}$ & $\mathbf{2 0 4 0}$ & $\mathbf{2 0 5 0}$ \\
\hline Number of plants & 0 & 0 & 35 & 80 & 169 & 258 \\
\hline New Capacity, GWt & 0 & 0 & 84 & 192 & 406 & 619 \\
\hline Avoided emissions, Mt & 0 & 0 & 115 & 259 & 548 & 836 \\
\hline HTGR CTL Plants & 0 & 0 & 3 & 7 & 16 & 24 \\
\hline Number of Plants & 0 & 0 & 40 & 92 & 211 & 317 \\
\hline New Capacity, GWt & 0 & 0 & 11 & 25 & 54 & 82 \\
\hline Avoided emissions, Mt & & & &
\end{tabular}

Clearly an aggressive application of HTGR technology is assumed. The $\sim 250$ plants assumed for supplying process heat and energy to industrial processes is not large compared with the number of natural gas fired plants that are currently in service in the US supplying energy to these plants. However, the applications to BTL/CTL would represent a departure from current practice; there is not currently a large use of CTL in the U.S. However, such deployment of these BTL/CTL plants would result in a significant reduction in the need to import oil, make productive use of one of our most abundant forms of energy, (e.g., coal) and provide a market for coal as its use is reduced for the production of electricity.

This level of deployment of HTGR plants will require a consolidated effort to reduce the emissions from burning of natural gas in these processes; to improve the environment and to make this important natural resource available for more productive purposes. Achieving this will require a significant increase in the industrial infrastructure for supply of large vessels, reactor fuel, pumps, valves, piping, the engineering, procurement and construction organizations required to design and build the plants and companies to operate them. As discussed more below, this would increase jobs and provide a solid manufacturing and operating base to the U.S. economy.

\section{$\underline{\text { Reductions in Imports of Crude Oil }}$}

The assumed deployment of the HTGRs in BTL/CTL plants results in a production capacity in 2050 of $\sim 2.4$ million BPD of synthetic fuels. This production rate is $\sim 25 \%$ of the rate at which the U.S. imported crude oil in 2008 ( $~ 9.75$ million barrels per day [EIA 2010, Table 11]). The use of this quantity of synthetic fuels to replace crude based gasoline, LPG, diesel and/or naphtha (a feedstock for petrochemical processes and gasoline production) production would have a large impact on reducing the need to import crude oil. This combined with the reductions in reliance on conventional gasoline and diesel cited in the preceding discussion of the transportation initiative would reduce the need to import crude oil in 2050 significantly, if at all.

Figure 4-12 shows the sum of all of the initiatives through deployment of the HTGR technology relative to meeting the final Objective \#3 - Reduce emissions to $20 \%$ of 1990 levels in 2050. A balance of $\sim 2370 \mathrm{Mt}$ of $\mathrm{CO}_{2}$ emission reductions are required to meet the objective. This can be achieved through deployment of a mix of Coal CCS and LWR Advanced Nuclear plants as discussed in the next section. 


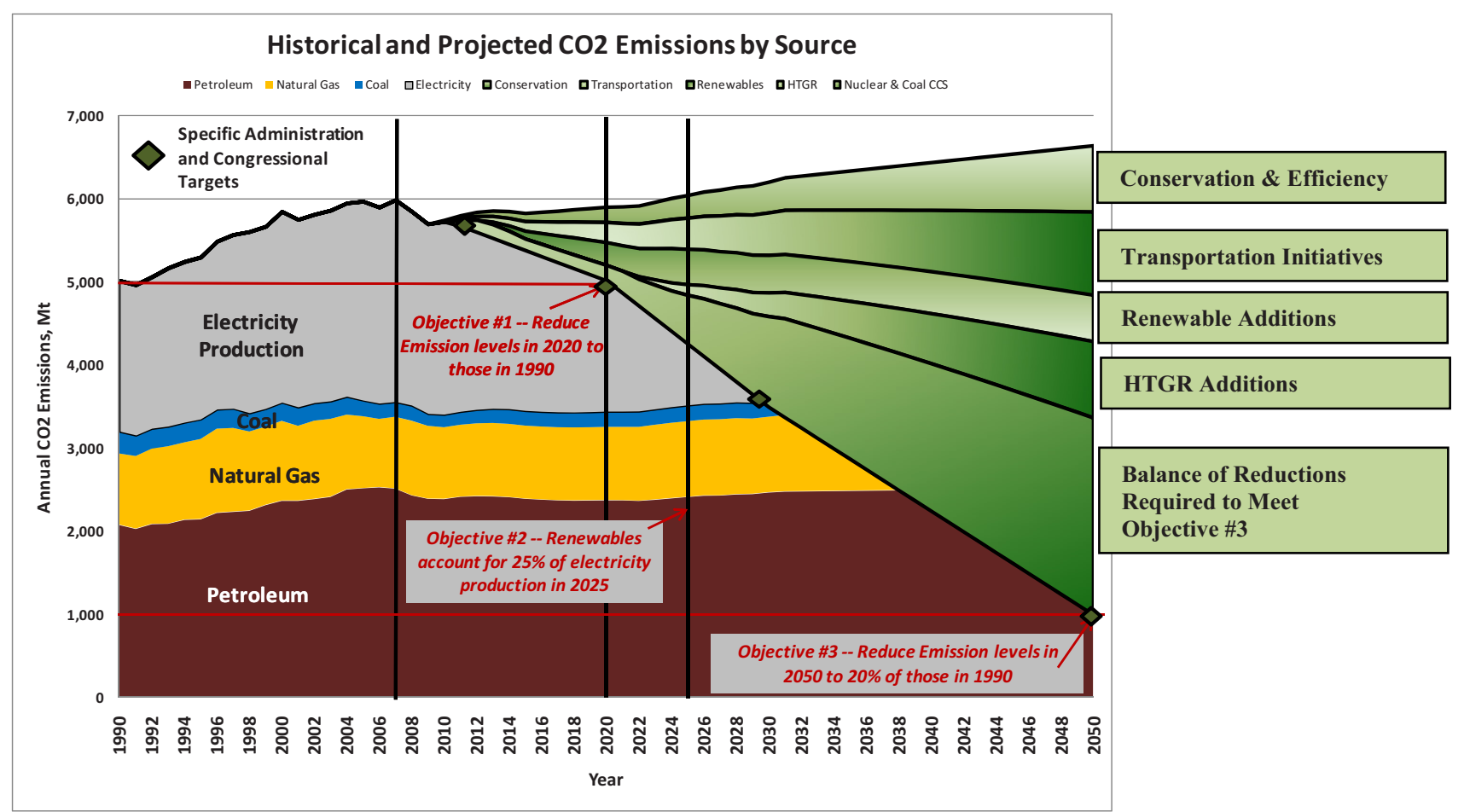

Figure 4-12. Summary of the impact of initiatives through HTGR Deployment on reducing emissions.

\subsection{Deployment of Nuclear and Coal CCS Plants Through 2050}

\subsubsection{Deployment of Coal Plants with Carbon Capture and Sequestration (CCS)}

No coal plants with CCS have been deployed as yet at the time of this writing. EPRI [EPRI2008] examined the status of development of these plants and concluded that the earliest one of these would be on-line was in 2020. EPRI stated that there is considerable uncertainty in whether this date would be met so the EPRI analyses were performed assuming the technology would not be available until 2030. For the purposes of this paper it is assumed that these plants will be available by 2020 . This will require emphasis on development requiring government support for the initial construction. Provisions for such government support are included in HR2454 and S-1733 bills pending in Congress. Other alternative applications of coal for electricity production, such as oxygen fired plants ${ }^{i}$ and Integrated Gasification Combined Cycle (IGCC) plants may also be available.

It is assumed that $\sim 4.5 \%$ of the electricity production in 2050 will be satisfied by deployment of some form of lower emitting coal plants such as Coal CCS plants with the characteristics summarized in Table 4-4. This relative low level of deployment reflects the uncertainty in the technical and economic viability of these alternatives. The following table summarizes the results for deployment of Coal CCS plants for this assumption.

i. A significant amount of oxygen is produced in nuclear hydrogen production plants that could be used to supply an oxygen fired coal plant if contiguous location of these plants was practical. 
Table 4-11. Deployment of Coal CCS plants.

\begin{tabular}{|c|c|c|c|c|c|}
\hline \multirow{2}{*}{ Energy Initiative } & \multicolumn{5}{|c|}{ Renewable Scenario 2} \\
\hline & 2016 & 2020 & 2025 & 2030 & 2050 \\
\hline$\%$ of Production & $0.0 \%$ & $0.7 \%$ & $1.5 \%$ & $2.3 \%$ & $4.5 \%$ \\
\hline Delta Production, Bkwhe & 0 & 31 & 72 & 119 & 268 \\
\hline Projected Total Prod, Bkwhe & 0 & 31 & 72 & 119 & 268 \\
\hline Delta Capacity, Mwe & 0 & 4,800 & 11,200 & 18,400 & 41,600 \\
\hline Number of Plant & 0 & 6 & 14 & 23 & 52 \\
\hline Delta avoided emissions & 0 & (35) & (73) & $(117)$ & $(262)$ \\
\hline
\end{tabular}

The $\sim 260 \mathrm{Mt}$ of emissions avoided through deployment of these plants obtains a balance of $\sim 2100 \mathrm{Mt}$ that will be achieved through deployment of additional ALWRs

\subsubsection{Deployment of Additional Advanced Light Water Reactors}

Table 4-12 summarizes the required deployment of Advanced Light Water Reactors (ALWR) to meet both Objective \#1 in 2020 and \#3 in 2050. This shows that an addition of $2300 \mathrm{GWe}$ of nuclear power is required to that projected to be in place by the EIA in 2050 .

Table 4-12. Deployment of LWRs.

\begin{tabular}{|l|c|c|c|c|c|}
\hline \multirow{2}{*}{\multicolumn{1}{c|}{ Energy Initiative }} & \multicolumn{5}{c|}{ Year } \\
\cline { 2 - 6 } & $\mathbf{2 0 1 6}$ & $\mathbf{2 0 2 0}$ & $\mathbf{2 0 2 5}$ & $\mathbf{2 0 3 0}$ & $\mathbf{2 0 5 0}$ \\
\hline & & & & & \\
\hline \% of Production & $23 \%$ & $23 \%$ & $31 \%$ & $40 \%$ & $58 \%$ \\
\hline Delta Production, Bkwhe & 164 & 174 & 598 & 1,129 & 2,461 \\
\hline Projected Total Prod, Bkwhe & 997 & 1,050 & 1,480 & 2,019 & 3,417 \\
\hline Delta Capacity, Mwe & 20,400 & 21,600 & 74,400 & 140,400 & 306,000 \\
\hline Number of Plant & 17 & 18 & 62 & 117 & 255 \\
\hline Delta avoided emissions & $(147)$ & $(151)$ & $(513)$ & $(972)$ & $(2,105)$ \\
\hline
\end{tabular}

The substitutions of Renewable, Nuclear ALWR and Coal CCS plants for coal and natural gas plants on the grid over the period $2010-2050$ assumed in this paper results in $\sim 12 \%$ of the electricity production projected for 2050 using conventional coal $(\sim 2 \%)$ and conventional natural gas $(\sim 10 \%)$ plants. As stated in the preceding discussion on renewable electricity production, it is judged that some fossil based cycleable electricity production capacity will be necessary to stabilize the grid with the $25 \%$ of production using renewable technologies required to meet Objective \#2. There is not sufficient experience nor analysis available at the time of this writing on the effect of this much renewable production on grid stability. The $12 \%$ of fossil power that is retained on the grid in 2050 will accommodate fluctuations in availability at a little less than half of the total renewable production assumed. (Note that about $5 \%$ of this renewable production is hydro-based. This leaves about $20 \%$ that has a fluctuating power characteristic. The hydro-based power can also be cycled to assist in stabilizing the grid.) Over the next several decades as more renewable comes on line and as the coal and natural gas plants are retired and replaced with nuclear and coal CCS plants the requirements for cycleable power generation will become evident and the mix of power technologies adjusted to ensure that the grid remains stable. 
The build out of ALWR plants assumed herein is significantly greater than that projected by EIA; (increases as a percent of total production about 2 times current EIA projections). On economic and emission reduction bases, substitution of ALWRs for conventional coal and natural gas fired electric power production plants is the most cost-effective of the other nonemitting alternatives (see Table 5-2). The assumption is equivalent to a three-fold increase in the number of LWR plants on-line over the next four decades with a total of $\sim 350$ plants. Note there are currently 104 commercial nuclear plants operating in the United States. This build out is judged to be achievable considering the first deployment of almost 125 plants in the first couple of decades of deploying the current fleet of plants and the advancement in technology for design, construction and operation of the current ALWRs. As noted previously there are over 30 plants in the early process of getting a license to construct and operate in the United States. What is required is completing the government commitment to support the licensing and construction of the first few plants under the NP2010 and EPAct 2005 programs to demonstrate the viability of this power production alternative. [As this paper was being finalized the government announced issue of loan guarantees for two nuclear plants as part of these programs.] This build out of LWRs will also re-vitalize the industries that support design, construction and operation of these plants adding jobs and strengthening the manufacturing sector of the U.S. economy.

\subsubsection{Final State to Meet Emission Objectives}

Figure 4-13 summarizes the complete deployment of actions to address the Administration and Congressional emissions reduction initiatives for the two Renewable Energy Addition scenarios.

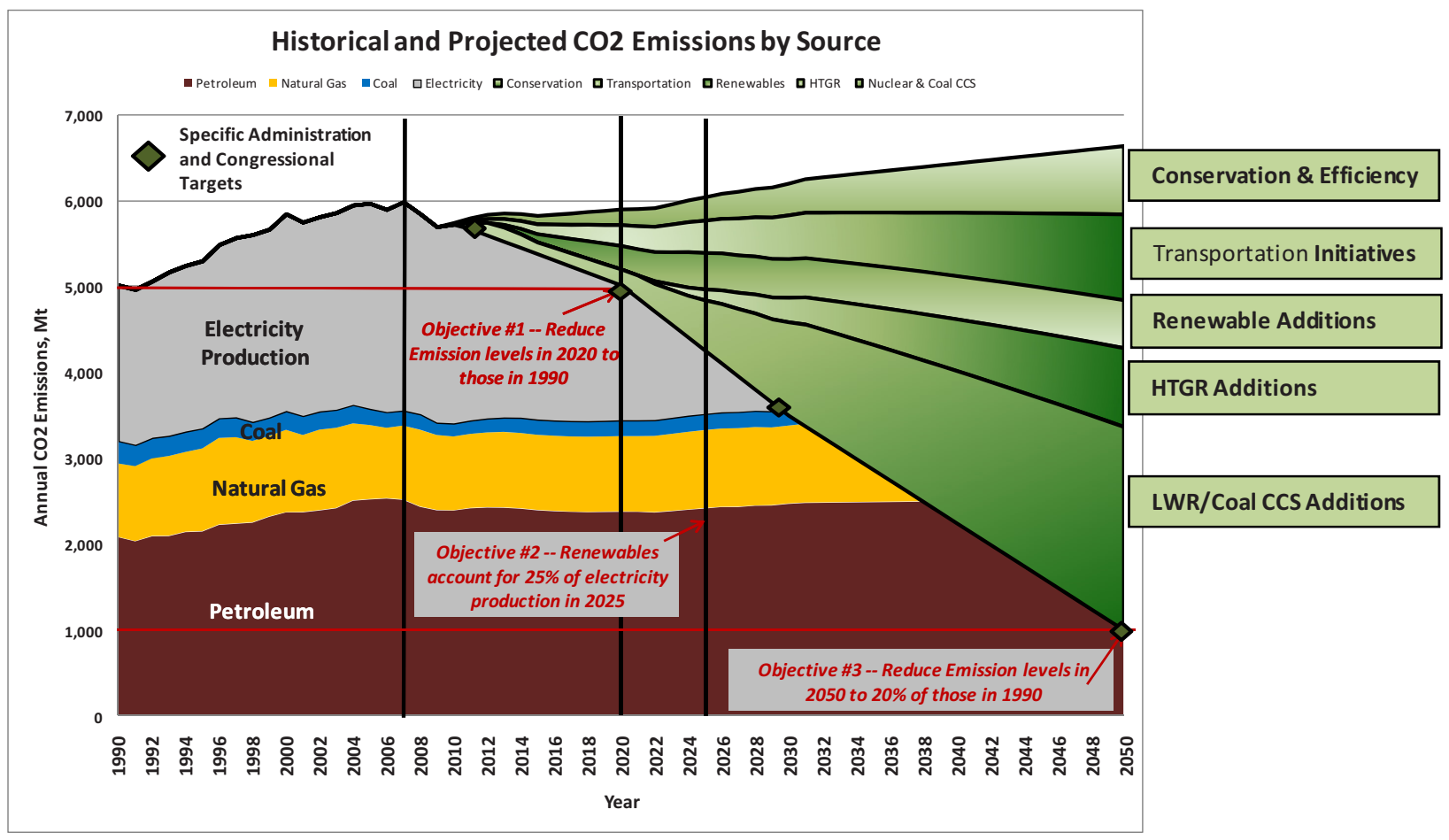

Figure 4-13. Summary of the impact of all initiatives on reducing emissions. 


\subsection{Additional Considerations}

\subsubsection{Infrastructure, Supply of Engineering, Materials and Equipment}

This report has focused on estimating the contributions of the various ways that $\mathrm{CO}_{2}$ emissions can be reduced and in the process of reducing emissions how these changes can improve energy security, reduce price volatility and provide more efficient use of limited natural resources. Naturally, though, there will be additional consequences of these changes at the scale proposed. Some of them are reviewed here.

The preceding chapters have discussed the various kinds of energy facilities required under this report's scenarios for the future. Not included is the support infrastructure for designing, constructing and operating those plants. Also not included for renewable energy are the power transmission lines needed to carry electricity from areas with good wind resources, solar potential or geothermal deposits to where the demand is. It will also be necessary to install pipelines to move synthetic fuels from coal-to-liquids plants, and other pipelines to carry captured carbon dioxide to ultimate sequestration sites. In addition, the bridges, highways, and railroads serving new power plant sites must be sufficient both to support the weight of units transported in as well as have sufficient capacity that delivery of components or construction materials can be done without creating delays for all traffic on the roads or railroads.

Achieving the objectives of the Administration and Congress for $\mathrm{CO}_{2}$ emissions reductions will require significant capital investment for design and construction work over the next four decades. Because the general types of systems to be built will be known well before their construction is committed, there is a great opportunity for a concerted program of research and development in manufacturing and construction to facilitate this construction, speeding its completion and holding down the overall costs. For example, an effort to improve the materials and practices used for large construction projects or to improve the factory-based manufacturing of wind turbines, composite-based vehicles, or components of carbon-capture systems could lead to large cost savings in the next 40 years.

Designing and building these facilities will require a large number of engineers of many types. A study on the manpower needs implied by the facilities discussed in this report would allow universities to plan for their education. A federally funded program of manufacturing and construction R\&D (which would tend to flow into many engineering departments) would assure that the faculties are available to teach these new engineers.

It is judged the required increases in engineering, manufacturing, equipment supply, construction and plant operating infrastructure to meet the emissions reduction objectives will need to be U.S. based to ensure availability of the necessary equipment, materials and resources necessary to complete this work. Similar build-outs will be taking place internationally as the economies and needs for additional power demands are met in the major developing countries, (e.g., China, India). This international build out will not necessarily include emissions reduction objectives but will take resources from the build out effort in the United States. This possibility presents an opportunity for the United States to use the resourcefulness it has demonstrated in the past to develop and implement viable solutions to major problems such as material supply, (e.g., developing and substituting composite materials for scarce metals), engineering, (e.g., improving designs to use modular construction, promote easier and more efficient operation), and fabrication, manufacturing and construction methods to reduce time and cost for constructing the plant. As shown below the total costs estimated for the completion of these initiatives are a reasonable fraction of the U.S. GDP so will add significant numbers of jobs and stimulation to the production sector of the economy. About 8 million man years of effort is estimated required to complete the infrastructure changes over the 40 year period of this strategy. On average this would require an additional labor force over the 40 year period of about 200,000. About 350,000 permanent jobs would also be developed in the production portion of the revised energy infrastructure. An additional several hundred thousand jobs 
would be required to support continued operation, maintenance and upgrade of the revised energy infrastructure.

The United States has the capabilities and has shown the ability to address these needs with innovation and economy. Consistent and focused attention to addressing these needs domestically could make the United States a principal competitive supplier of the technologies, engineering, equipment and construction methodologies internationally. Such an effort could spread to and reinvigorate the broader manufacturing industry in the United States potentially promoting a material shift toward a production oriented economy in the United States away from the services economy that has dominated the last few decades.

\subsubsection{Capital Markets}

Completion of any strategy to realize the objectives of this energy infrastructure transformation will require substantial capital investment. The government will need to institute programs with the objective of transforming the energy infrastructure, likely with the focus of reducing emitting technologies in the United States, and provide tax incentives and loan guarantees across the full range of energy production and consumption sectors to ensure the availability of the needed capital. The government support, however, will not be sufficient for the long term if the strategies are not economically viable. The investors and the owner/operators must achieve acceptable returns on capital or the capital markets will dry up. The investment will be from the private sector, but will require substantial government support to ensure the availability of capital. A following section discusses the estimated cost for implementation of the strategies evaluated herein and the expected effect on the cost of energy when implemented.

\subsubsection{Stabilizing Energy Costs}

Full implementation of this strategy will promote stability in the cost of energy by transferring the sources of energy from imports to indigenous resources and by insulating the prices of energy from the large fluctuations in the prices of crude oil and natural gas that have characterized these dominant sources of the U.S. energy portfolio. This stability will come with an increase in the overall average price of energy. However, the stability in prices will support better predictions of industrial, commercial and residential energy costs supporting a more stable economy. A following section provides an estimate of the average increase in energy costs for the energy transformation scenario evaluated.

\subsubsection{Reductions in Crude Oil Imports Improves Energy Security and Energy Price Stability}

As noted in the discussions of the Transportation Sector initiatives and HTGR application to clean production of synthetic transportation fuels, a benefit of these proposed changes is the reduction in imported petroleum. In 2050 the Transportation Initiatives would reduce gasoline consumption by $\sim 4.8$ million barrels per day from that currently projected by DOE-EIA or $\sim 50 \%$ of total gasoline consumption in 2009. The Synthetic fuels production using HTGR would produce an additional 2.4 million barrels per day (bpd) of synthetic fuels; $\sim 25 \%$ of the crude oil imported in 2008. As shown in the figure from the EIA [DOE2008], a typical 42 gallon barrel of crude oil produces 9.21 gallons of diesel and 19.15 gallons of gasoline. Synthetic fuels could also be used for heating oil and jet fuel.

Accordingly, the reductions in gasoline consumption and the significant production of synthetic fuels using the

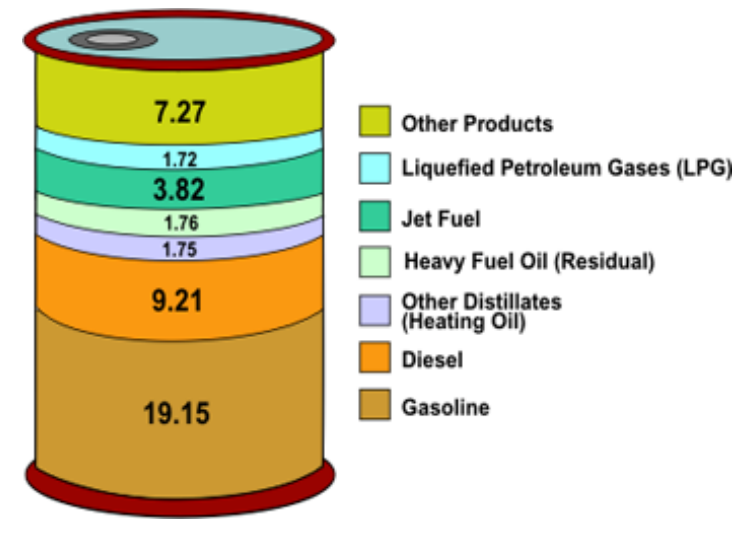


HTGR would have impact on reducing the United States import of crude oil. To put this in perspective, the EIA predicts for 2030 that the United States will produce 10.06 million barrels per day of conventional and 2.43 million bpd of unconventional (biomass, oil sands, oil shale, etc) crude oil or crude oil equivalent against a consumption of 20.92 million bpd, for a net import of 8.43 million bpd. The $\sim 7.2$ million bpd of reduction in consumption of gasoline and diesel in 2050 could more than eliminate imports and the consequent concerns about security of supply. The reduction in imports would also support more stability in the price of transportation fuels since the cost of coal used for synthetic fuel production has been relatively steady for decades. This would provide a market for coal that is no longer in use to produce electricity as a result of the Electricity Energy sector initiatives for replacing coal fired plants with non-GHG emitting plants. 


\section{COSTS}

\subsection{Capital Expenditures}

A rough order of magnitude estimate of the costs for implementation of the emissions reduction initiatives was made using cost data from [AEO2009e, NEI2009, NGNP2007]. This cost data is summarized in Table 5-1. The data for the existing coal and conventional combined cycle plants are representative of average costs for these plants.

The construction costs for new plants, (e.g., coal w/CCS, Advanced Nuclear, Wind (land based 90\% and off-shore 10\%), and HTGR) were applied to the number of plants estimated to be required to meet the Administration and Congressional objectives for each renewable scenario. Figure 5-1 shows the estimated accumulative investment required for the strategies developed herein. The estimates are in \$2007 consistent with Table 5-2. Note that these cost estimates do not include any costs for the transportation initiatives nor for the infrastructure costs discussed in the preceding section. The infrastructure costs will add several billion dollars to the cost estimates.

The total required expenditures will be about $\$ 3.85 \mathrm{~T}$, and the expenditure by year will be $\sim \$ 100 \mathrm{~B}$ per annum, which is about $0.5 \%$ of the GDP projected by DOE-EIA for 2030 [AEO2009a], $(\sim 20,000 \mathrm{~B}$ in \$2000). As noted in the prior section sustaining this expenditure rate will require that the investment provide a market return. This will result in an increase in the cost of energy as these investments are made. The next section estimates the increase for each scenario.

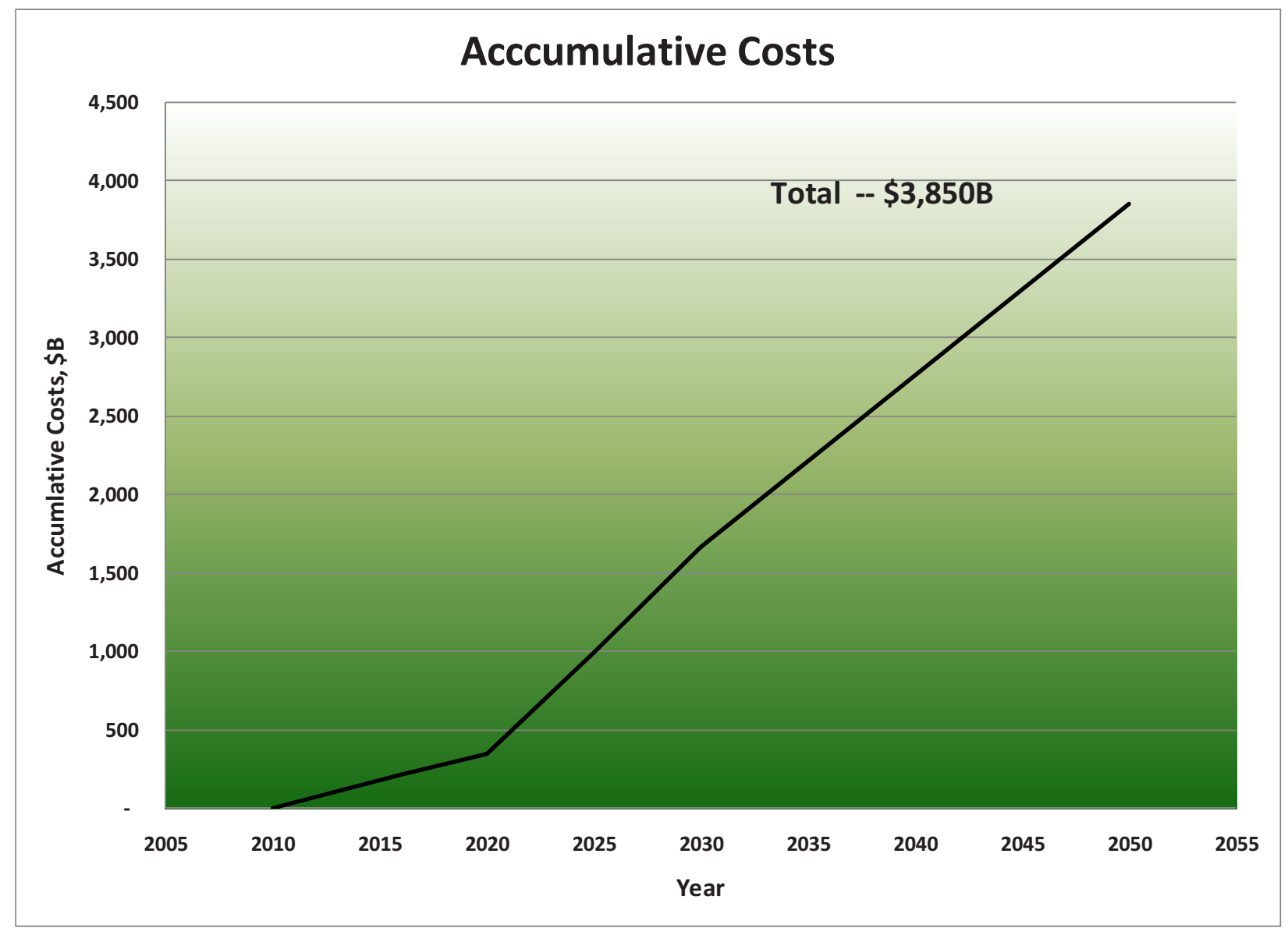

Figure 5-1. Estimate of accumulative costs for each scenario. 

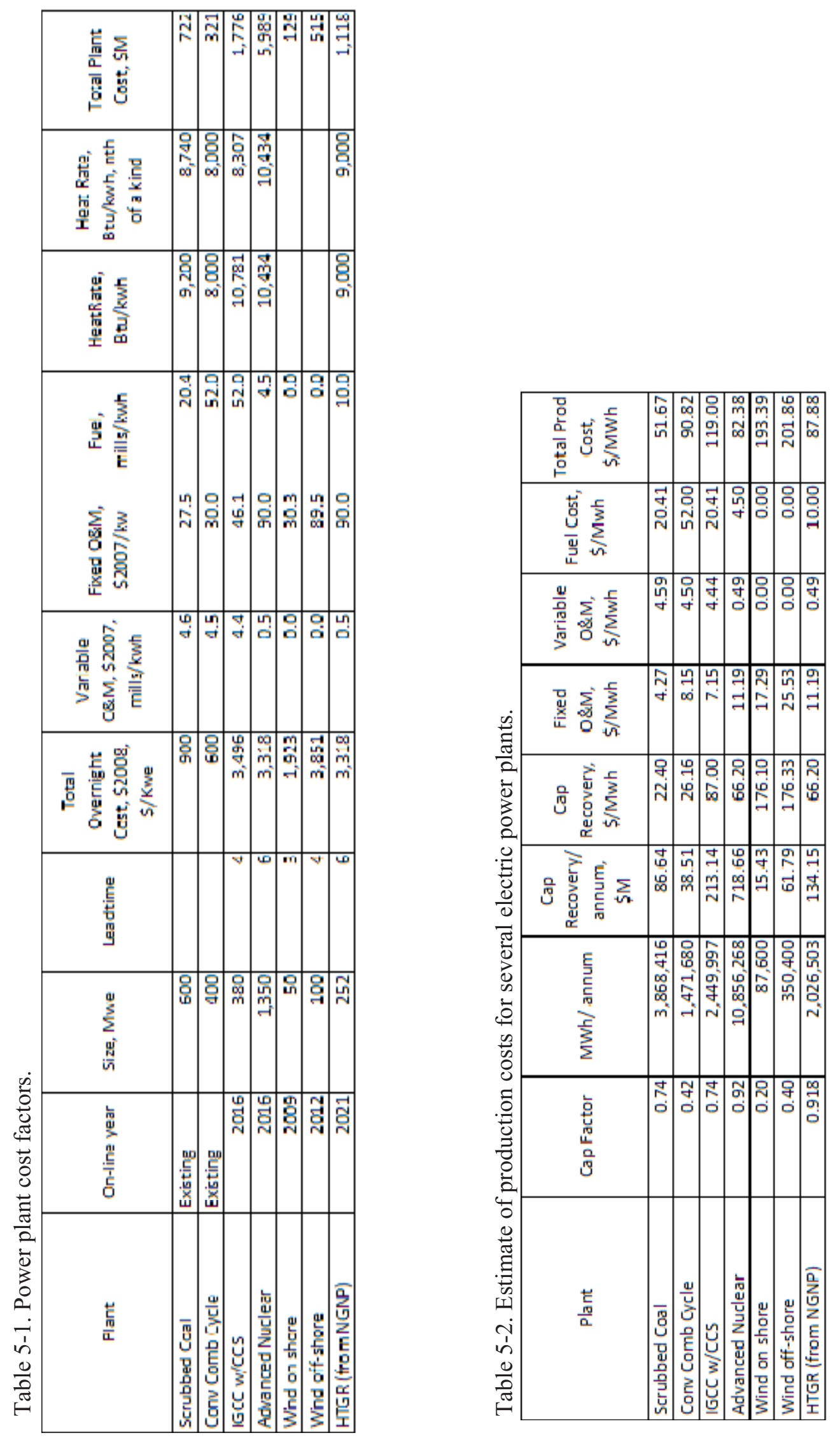
It should be noted that these costs are not compared against costs that would be expended to sustain the energy supply in each of these sectors over the next four decades. Based on the low growth rate that is projected in the energy sectors and the age of plants in the electricity sector this is not considered a major factor. This factor can be included in refinement of these analyses, if warranted. In any event whether it is in like-for-like replacement or replacements and upgrades to achieve a transformation of the energy infrastructure a significant expenditure is required.

\subsection{Estimate of Increased Cost of Energy}

The capital and operating costs including fuel from Table 5-1 were used to develop a levelized production cost per MWh for each of the processes used in the evaluation. The portion of the capital cost attributable to the production cost was calculated assuming a 33.7\% factor applied to the Overnight Cost that covers Owners Cost and Interest During Construction and a 12\% Capital Recovery Factor. Table 5-2 summarizes the results.

Figure 5-2 shows the projected cost of electricity over the next four decades for the recommended strategies for replacing current coal and natural gas plants with nonemitting sources of electricity production and the deployment of HTGR plants in co-generation and synthetic fuel production applications. The increase ( $\sim 54 \%$ over the 4 decade period) is judged to be representative of the increase in the cost of energy in general. (Note that the EPA estimate of HR2454 projects the same increase in the real cost of energy over the same period for the provisions of that bill (EPA2009a, EPA2009b].)

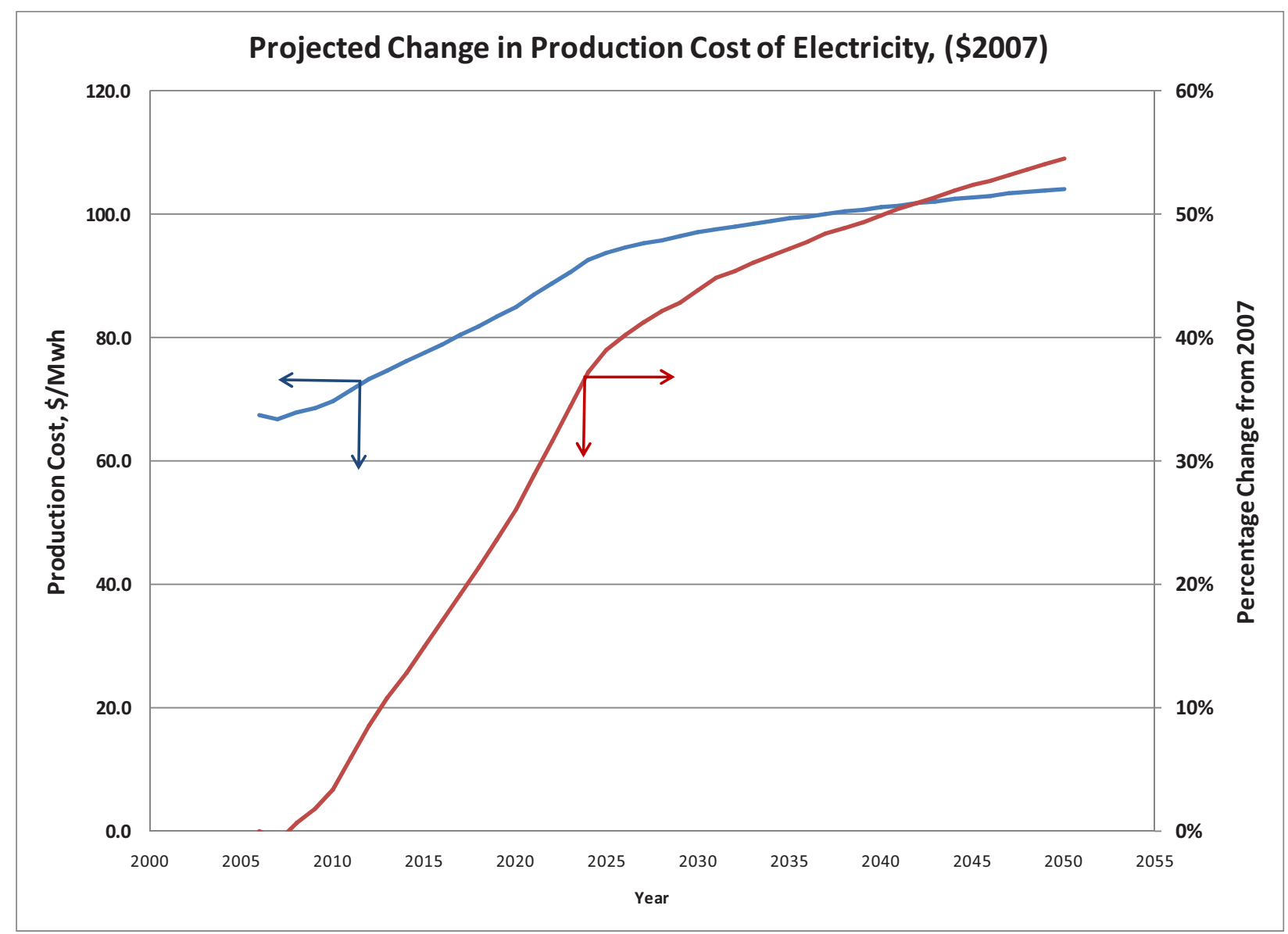

Figure 5-2. Projected change in the cost of electricity production. 


\section{REFERENCES}

[ADMIN2008] Obama/Biden Policy Paper: "Promoting a Healthy Environment"

[ADMIN2009] THE WHITE HOUSE, Office of the Press Secretary, For Immediate Release, May 19, 2009, "Below is a fact sheet and list of attendees at today's Rose Garden announcement", Obama Administration National Fuel Efficiency Policy

[AEO2009a] DOE/EIA-0383(2009), Annual Energy Outlook 2009 with Projections to 2030, March 2009 and DOE/EIA-0554(2009), "Assumptions to the Annual Energy Outlook 2009 with Projections to 2030", March 2009

[AEO2009b] EIA Annual Energy Outlook 2006, Table 48, "Light-Duty Vehicle Miles Traveled by Technology Type" and Table 48. Light-Duty Vehicle Miles Traveled by Technology Type, EIA AEO 2009

[AEO2009c] DOE/EIA-0383(2009), Table 16. Renewable Energy Generating Capacity and Generation (gigawatts, unless otherwise noted), March 2009

[AEO2009d] DOE/EIA AEO 2009, Table 10.1, Renewable Energy Production and Consumption by Primary Energy Source, 1949-2008

[AEO2009e] DOE/EIA AEO 2009 Assumptions, Table 8.2 Cost and Performance Characteristics of New Central Station Electricity Production Technologies

[AEO2010] DOE/EIA Annual Energy Outlook 2010 Early Release, December 2009

[Agrawal2007] Rakesh Agrawal, et. Al., Sustainable fuel for the transportation sector, PNAS, March 20, 2007, Vol. 104, No. 12

[Benitez2007] Benitez, L. E., et.al., "The economics of wind power with energy storage", Institute for Integrated Energy Systems, University of Victoria, PO Box 3055, STN CSC, Victoria, BC, V8W 3P6, Canada, Department of Economics, University of Victoria, PO Box, 1700, STN CSC, Victoria, BC, Canada V8W 2Y2, School of Public Administration, University of Victoria, Canada, Received 11 January 2006; received in revised form 5 July 2006; accepted 14 August 2006, Available online 6 March 2007, Energy Economics 30 (2008) 1973-1989, Science Direct

[CBO2009a] Congressional Budget Office, Cost Estimate, H.R. 2455, American Clean Energy and Security Act of 2009, June 5, 2009

[CBO2009b] Congressional Budget Office, "The Estimated costs to Households From the Cap-andTrade Provisions of H.R. 2454, June 19, 2009

[Chupka2008] Chupka, Marc W., Robert Earle, Peter Fox-Penner, Ryan Hledik, The Brattle Group, Transforming America's Power Industry: The Investment Challenge 2010-2030, , Prepared for The Edison Foundation, November 2008

[DOE 2007] DOE/EIA, Figure 1.1 Renewable Energy Consumption in the Nation's Energy Supply, 2007, Source: Energy Information Administration, Office of Coal, Nuclear, Electric and Alternate Fuels.

[DOE2008] DOE/EIA - Table 1 -- License Applications for Commercial Nuclear Reactors in the United States, Status as of December 31, 2008

[DOE2008] DOE/EIA Brochures, Diesel Fuel Prices, What Consumers Should Know, Brochure \#: DOE/EIA-X045, June 2008

[DOE2009a] DOE/EIA, Annual Energy Supply, 2009 
[DOE2009b] DOE/EIA, "Light Duty Diesel Vehicles: Efficiency and Emissions Attributes and Market Issues, 2. Comparison of Light-Duty Vehicle Greenhouse Gas Emissions", Report \# SR/OIAF(2009)02, February 2009

[DOE2009c] DOE/EIA-0095(2000)/2, Inventory of Nonutility Electric Power Plants in the United States 2000, January 2003

[DOE 2009d] DOE/EIA Short - Term Energy Outlook Supplement: The Implications of Lower Natural Gas Prices for the Electric Generation Mix in the Southeast, May 2009

[DOT2006] DOT HS 809952 Technical Report, "VEHICLE SURVIVABILITY AND TRAVEL MILEAGE SCHEDULES”, Published By: National Highway Transportation Safety Administration's National Center for Statistics and Analysis, January 2006

[DOT2009a] DOT, Table 4-23, Average Fuel Efficiency of U.S. Passenger Vehicles and Light Trucks, Bureau of Transportation Statistics, Research and Innovative Technology Administration, Department of Transportation, Washington, DC

[DOT2009b] DOT, Table 1-11, Number of U.S. Aircraft, Vessels, Vehicles and Other Conveyances, Bureau of Transportation Statistics, Research and Innovative Technology Administration, Department of Transportation, Washington, DC

[EPA2009a] Analysis of the American Clean Energy and Security Act of 2009, H.R. 2454 in the $111^{\text {th }}$ Congress, U.S. Environmental Protection Agency, Office of Atmospheric Programs, June 23, 2009

[EPA2009b] EPA Analysis of the American Clean Energy and Security Act of 2009, H.R. 2454 in the $111^{\text {th }}$ Congress, U.S. Environmental Protection Agency, Office of Atmospheric Programs, June 23, 2009 -- Appendix

[EPA2009c] EPA, Economic Impacts of S. 1733: The Clean Energy Jobs and American Power Act of 2009, October 23, 2009

[EPA 2009d] EPA-420-D-09-003, Draft Regulatory Input Analysis, Proposed Rulemaking to Establish Light Duty Vehicle Greenhouse Gas Emission Standards and Corporate Average Fuel Economy Standards, September 2009, US-EPA

[EPACT2005] Energy Policy Act of 2005

[EPRI2008]The Power to Reduce $\mathrm{CO}_{2}$ Emissions: the Full Portfolio, 2008 Economic Sensitivity Studies, 1018431

[FERC2005] FERC, UNITED STATES OF AMERICA FEDERAL ENERGY REGULATORY COMMISSION, 18 CFR Part 35 (Docket No. RM05-4-000), "Interconnection for Wind Energy and Other Alternative Technologies", (January 24, 2005)

[GREET2007] Transportation Fuel Cycle Analysis Model, GREET 1.7, developed by Argonne National Laboratory, Argonne, IL, released June 2007

[HR2454 2009] H.R. 2454, American Clean Energy and Security Act, "To create clean energy jobs, achieve energy independence, reduce global warming pollution and transition to a clean energy economy", $111^{\text {th }}$ Congress, $1^{\text {st }}$ Session

[IEA2009] IEA, Variability of Wind Power and other Renewables: Management Options and Strategies, International Energy Agency, 9, rue de la Fédération, 75739 Paris Cedex 15, antonio.pflueger@,iea.org

[INL2009b]INL/EXT-09-16942 Revision 0, Integration of High Temperature Gas-Cooled Reactors into Industrial Process Applications, October 2009

[INL2009c] INL/BEA Energy Security Initiative, Hybrid Energy Systems 
[IOWA2006] Iowa Stored Energy Park, 2006

[King2008] King, J., "Proposed Combined-cycle Power Plant Planning Assumptions", Sixth Northwest Conservation \& Electric Power Plan, Northwest Power and Conservation Council, Power Committee, Portland, OR, October 15, 2008

[MPR2008a] MPR-3181, Survey of HTGR Process Energy Applications, Revision 0, May 2, 2008

[MPR2008b] Number of High Temperature Gas-cooled Reactors that Could Hypothetically be Applied to U.S. Hydrogen Production and to Canadian Oil Sands Recovery, August 8, 2008

[NADA2008] NADA DATA 2008, National Automobile Dealers Association

[NATLACAD] Liquid Transportation Fuels from Coal and Biomass, Technological Status, Costs and Environmental Impacts, National Academy of Sciences, Nationals Academy of Engineering, National Research Council

[NEI2009] NEI, U.S. Electricity Production Costs and Components, 1995-2008, Nuclear Energy Institute

[NETL2007a] DOE/NETL-2007/1260, Baseline Technical and Economic Assessment of a Commercial Scale Fischer-Tropsch Liquids Facility, April 9, 2007

[NETL2007b] DOE/NETL-2007/1251, Alaska Coal Gasification Feasibility Studies- Healy Coal-toLiquids Plant, July 2007

[NETL2007c] DOE/NETL-2007/1298, Increasing Security and Reducing Carbon Emissions of the U.S. Transportation Sector: A Transformational Role for Coal with Biomass, August 24, 2007

[NETL2008] Daniel C. Cicero Technology Manager, National Energy Technology Laboratory, Hydrogen and Syngas, Status and Roadmap Coal-to-Liquids in the United States, CTLtec, Americas 2008, June 23 - 24, 2008

[NGNP2007a] NGNP Project Authorized by the Energy Policy Act of 2005, Section 641

[NGNP2007b] NGNP, Pre-conceptual Design Report, November 2007

[NGNP2009] NGNP Senior Advisory Board Recommendations on Plant Configuration, Functional and Operational Requirements, March and July 2009

[NHTSA2006] TITLE 49, UNITED STATES CODE, SUBTITLE VI. MOTOR VEHICLE AND DRIVER PROGRAMS PART C. INFORMATION, STANDARDS, AND REQUIREMENTS, CHAPTER 325, ADMINISTERED BY THE NATIONAL HIGHWAY TRAFFIC SAFETY ADMINISTRATION, U.S. Department of Transportation National Highway Traffic Safety Administration Office of Chief Counsel, June 2006

[NHTSA2009] Environmental Protection Agency, 40 CFR Parts 86 and 600, Department of Transportation National Highway Traffic Safety Administration, 49 CFR Parts 531, 533, 537, et al., Proposed Rulemaking To Establish Light-Duty Vehicle Greenhouse Gas Emission Standards and Corporate Average Fuel Economy Standards; Proposed Rule, September 28, 2009

[NP2010] Nuclear Power 2010

[Parsons2008] Parsons, B., et.al., "Impacts of Large Amounts of Wind Power on Design and Operation of Power Systems; Results of IEA Collaboration", NREL/CP-500-43540, June 2008

[S1733 2009] S-1733, Clean Energy Jobs and American Power Act of 2009

[Searchinger] Searchinger, T.D., et.al., "Fixing a Critical Climate Accounting Error", Science, Vol 326, October 23, 2009 
The following references were also consulted in preparation of this report that may be of interest to the reader:

- An Energy Transition Plan for the Administration and Congress, Institute for 21st Century Energy, U.S. Chamber of Commerce

- AREVA, "Competitiveness of Energy Sources for Electricity Production, Dinner-Debate at the Invitation of AREVA, September 5, 2006, Item Code: DD20060905

- $\quad$ AWEA Small Wind Turbine Global Market Study 2008

- DOE/GO-102008-2567, “20\% Wind Energy by 2030 ,Increasing Wind Energy’s Contribution to U.S. Electricity Supply”, July 2008

- EIA, "Nuclear Power: 12 Percent of America's Capacity, 20 Percent of the Electricity"

- EIA, Short-Term Energy Outlook Supplement: "The Implications of Lower Natural Gas Prices for the Electric Generation Mix in the Southeast", May 2009

- Energy Information Administration/Short-Term Energy Outlook - June 2009, Table 5c. U.S. Regional Natural Gas Prices (dollars per thousand cubic feet)

- FERC Hybrid Vehicle Presentation, “The Cashback Hybrid”, 2007

- Javier C. Palacios, et.al., "Levelized costs for nuclear, gas and coal for Electricity, under the Mexican scenario", Instituto Nacional de Investigaciones Nucleares México, palacios@nuclear.inin.mx, galonso@nuclear.inin.mx .

- Jayant Sathaye and Amol Phadke, "Cost and carbon emissions of coal and combined cycle power plants in India: Implications for costs of climate mitigation projects in a nascent market", LBNL 52915, International Energy Studies 2004

- New nuclear capital costs rising, but still competitive, MIT study says, Nucleonics Week, May 21, 2009

- Northwest Power Planning Council, New Resource Characterization for the Fifth Power Plan, "Natural Gas Combined-cycle Gas Turbine Power Plants", August 8, 2002

- Office of Integrated Analysis and Forecasting, EIA, "Greenhouse Gas Emissions in the United States 2007, Table 4-Greenhouse Gases and 100 Year Net Global Warming Potential”, Report \#: DOE/EIA0573(2007), Released Date: December 2008

- PJM Interconnection, LLC, “CONE Combined Cycle Revenue Requirements Update”, August 26, 2008

- Renewables Global Status Report 2009 Update, Renewable Energy Policy Network for the $21^{\text {st }}$ Century.

- Report \#:DOE/EIA-0554(2009), March 2009, Electricity Market Module, Coal Market Module, Petroleum Demand Module, Commercial Demand Module, Industrial Demand Module, Oil-Gas Module, Transportation Module

- Son of Waxman-Markey: More Politics Makes for a More Costly Bill, Web Memo, The Heritage Foundation, No.2450, May 18,2009, Revised and Updated June 16, 2009

- Table 9.10 Cost of Fossil-Fuel Receipts at Electric Generating Plants (Nominal Dollars per Million Btu, Including Taxes), EIA Monthly Energy Review, June 2009

- Tom Beer1,2, Tim Grant3, Richard Brown1, Jim Edwards4, Peter Nelson4, Harry Watson5 \& David Williams4, "Life-cycle Emissions Analysis of Alternative Fuels for Heavy Vehicles Stage 1", 1CSIRO Atmospheric Research, Aspendale, Vic. 2CSIRO Environmental Risk Network, Aspendale, 
Vic 3RMIT Centre for Design, Melbourne, Vic. 4CSIRO Energy Technology, North Ryde, NSW 5University of Melbourne, Dept. of Mechanical and Manufacturing Engineering, Parkville, Vic., CSIRO Atmospheric Research Report C/0411/1.1/F2 to the Australian Greenhouse Office, March 2000

- U.S. EPA, "Ways in Which Revisions to the American Clean Energy and Security Act Change the Projected Economic Impacts of the Bill, May 17, 2009 


\section{Appendix A}

\section{Summary of Administration and Congressional Objectives for Reducing Greenhouse Gas Emissions}




\section{Appendix A \\ Summary of Administration and Congressional Objectives for Reducing Greenhouse Gas Emissions}

\section{OBJECTIVES}

\subsection{Administration Objectives}

The current Administration has proposed the following as national objectives in addressing the issue of climate change:

- Objective \#1 ${ }^{\mathrm{j}}--$ by 2020

“... reduce [carbon] emissions to 1990 levels"

AEO2009 reports that in 1990 there were 5019 Million Metric tons [shortened to Mt for convenience] of $\mathrm{CO}_{2}$ emissions attributable to energy production and consumption ${ }^{k}$ and that if no action is taken the emissions in 2020 are projected to be $5905 \mathrm{Mt}$. To meet Objective \#1 the emissions in 2020 will have to be reduced by $\sim 900 \mathrm{Mt}$.

- Objective \# 2 - by 2025

“... 25 percent of electricity consumed in the United States is derived from clean, sustainable energy sources, like solar, wind and geothermal"

AEO2009 reports that $15.9 \%$ of electricity production in 2025 is projected to be from renewable sources. EIA includes hydro-electric as a renewable source of electricity and this accounts for about $7 \%$ of the production in 2025 . An additional $\sim 10 \%$ of renewable production will need to be added to the production mix in 2025 to meet this initiative. Hydroelectric production is not projected to grow significantly in the future since most viable sites have already been developed. Accordingly, the increase in renewable will come from nonhydro-electric sources such as wind, solar, wood, biomass, geothermal.

- Objective \#3 - by 2050

“... reduce carbon emissions by the amount scientists say is necessary: 80 percent below 1990 levels"

$80 \%$ below 1990 levels is an annual emission rate of $\sim 1005 \mathrm{Mt}$. Extension of the AEO 2009FIF emission projections predicts that CO2 emission levels will be at $6645 \mathrm{Mt}$ in 2050 if no action is taken to reduce them. Accordingly $\mathrm{CO} 2$ emissions will need to be reduced by $5640 \mathrm{Mt}$ to meet Objective \#3.

The Administration also has an initiative to improve the new car gas mileage as a measure to reduce emissions in the transportation sector as follows:

- Increase vehicle mileage by $\sim 5 \%$ per year to achieve an average new car fleet mileage of $35.5 \mathrm{mpg}$ by 2016

j. The objectives have been numbered for convenient reference herein. These objectives were not numbered in the referenced policy paper.

k. The figures following each objective show the impact of the objective statement on current projections by DOE EIA in the referenced Annual Energy Outlook 2009 data

1. The DOE-EIA Annual Energy Outlook for 2009 provides projections to 2030, the 2050 value is based on extrapolation of the average rate of change projected by AEO2009 over the period 2010 to 2030. 
- The current CAFÉ requirements on new car fleet mileage are at $27.5 \mathrm{mpg}$.

\subsection{Congressional Objectives}

At the time of this writing a Congressional bill HR 2454 has been passed and a similar bill S1733 is being debated in the Senate. Both of these bills have similar objectives. Since it has been passed, the following summarizes the objectives of HR2454:

- Cap emissions [assumed to be GHG emissions] at 2005 levels beginning in 2012

- Require a reduction of 17 percent below the 2005 baseline by 2020

- By 2030 emissions must fall by 42 percent below the baseline and by 2050 by 83 percent.

- Utilities shall get 15 percent of their power from renewable sources by 2020

This bill also proposes a cap and trade program on GHG emissions with wide-spread allowance allocations and domestic and international offsets with extensive rebates of governmental and energy supplier revenues from allowances to protect consumers from higher energy costs associated with these emissions reductions.

The objectives of HR2454 generally align with the Administration objectives.

Several assessments of the costs of this bill to the government and the consumer have been performed. Two of these by the Congressional Budget Office and the U.S. Environmental Protection Agency are compared to the strategy discussed herein in a companion paper. 